\title{
Antiangiogenic therapy reverses the immunosuppressive breast cancer microenvironment
}

\author{
Wuzhen Chen ${ }^{1,2}$, Lesang Shen ${ }^{1,2}$, Jingxin Jiang ${ }^{1,2}$, Leyi Zhang ${ }^{2}$, Zhigang Zhang ${ }^{2}$, Jun Pan ${ }^{2}$, Chao $\mathrm{Ni}^{1,2^{*}}$ and \\ Zhigang Chen ${ }^{1,2^{*}}$
}

\begin{abstract}
Tumor angiogenesis induces local hypoxia and recruits immunosuppressive cells, whereas hypoxia subsequently promotes tumor angiogenesis. Immunotherapy efficacy depends on the accumulation and activity of tumorinfiltrating immune cells (TIICS). Antangiogenic therapy could improve local perfusion, relieve tumor microenvironment (TME) hypoxia, and reverse the immunosuppressive state. Combining antiangiogenic therapy with immunotherapy might represent a promising option for the treatment of breast cancer. This article discusses the immunosuppressive characteristics of the breast cancer TME and outlines the interaction between the tumor vasculature and the immune system. Combining antiangiogenic therapy with immunotherapy could interrupt abnormal tumor vasculature-immunosuppression crosstalk, increase effector immune cell infiltration, improve immunotherapy effectiveness, and reduce the risk of immune-related adverse events. In addition, we summarize the preclinical research and ongoing clinical research related to the combination of antiangiogenic therapy with immunotherapy, discuss the underlying mechanisms, and provide a view for future developments. The combination of antiangiogenic therapy and immunotherapy could be a potential therapeutic strategy for treatment of breast cancer to promote tumor vasculature normalization and increase the efficiency of immunotherapy.
\end{abstract}

Keywords: Antiangiogenic therapy, Immunotherapy, Breast cancer, Tumor microenvironment (TME)

\section{Introduction}

The signal imbalance between proangiogenic and antiangiogenic molecules leads to tumor vascular dysfunction $[1,2]$. Angiogenesis, which refers to the formation of abnormally immature vessels, often accompanies tumorigenesis. The abnormal structure of the tumor vasculature and restricted blood perfusion prevent immune cells from infiltrating tumors efficiently, which results in an unbalanced and immunosuppressive tumor microenvironment (TME) [2].

\footnotetext{
* Correspondence: nicaho428@zju.edu.cn; chenzhigang@zju.edu.cn ${ }^{1}$ Department of Breast Surgery (Surgical Oncology), Second Affiliated Hospital, Zhejiang University School of Medicine, 88 Jiefang Road, Hangzhou 310000, Zhejiang Province, China

Full list of author information is available at the end of the article
}

Revolutionary changes in cancer treatment have occurred with the continuous development of immune checkpoint blockade (ICB) immunotherapy. However, only $10-30 \%$ of breast cancer patients benefit from ICB immunotherapy [3]. Hence, there is a need to explore how to intensify treatment based on immunotherapy to achieve more survival benefits. Although ICB could reactivate dysfunctional or depleted $\mathrm{T}$ cells, these reactivated $\mathrm{T}$ cells could not infiltrate into the center of solid tumors to exert antitumor effects. Antiangiogenic therapy has been widely studied for a long time [4], and most antiangiogenic agents target vascular endothelial growth factors (VEGFs) and VEGF receptors (VEGFRs) [5]. In preclinical research, antiangiogenic therapy has been shown to reverse abnormal tumor blood perfusion,

C C The Author(s). 2021 Open Access This article is licensed under a Creative Commons Attribution 4.0 International License, which permits use, sharing, adaptation, distribution and reproduction in any medium or format, as long as you give appropriate credit to the original author(s) and the source, provide a link to the Creative Commons licence, and indicate if changes were made. The images or other third party material in this article are included in the article's Creative Commons licence, unless indicated otherwise in a credit line to the material. If material is not included in the article's Creative Commons licence and your intended use is not permitted by statutory regulation or exceeds the permitted use, you will need to obtain permission directly from the copyright holder. To view a copy of this licence, visit http://creativecommons.org/licenses/by/4.0/ The Creative Commons Public Domain Dedication waiver (http://creativecommons.org/publicdomain/zero/1.0/) applies to the data made available in this article, unless otherwise stated in a credit line to the data. 
promote immune cell infiltration and normalize the immune TME $[6,7]$. Given this evidence, tumor angiogenesis could interact with the immune TME. Targeting angiogenesis represent a potential option to reverse tumor-associated perfusion abnormalities and the immunosuppressive microenvironment.

In this article, we reviewed the crosstalk between the breast cancer vascular system and the immune microenvironment, discussed the mechanisms by which antiangiogenic therapy reverses the immunosuppressive TME and emphasized the clinical evidence of antiangiogenic therapy plus immunotherapy. We also discussed biomarkers to monitor the response to antiangiogenic agents plus immunotherapy and the challenges in this emerging field.

\section{Immunosuppressive TME induced by tumor angiogenic factors}

Enhanced angiogenesis is the hallmark of cancer. Tumor vasculature is unevenly distributed and chaotic [8]. On the one hand, restricted tumor vascular perfusion blocks the transfer of chemotherapeutic and immunotherapeutic agents to the tumor interior and eliminates infiltrated immunosuppressive cells in the TME. On the other hand, tumor-associated vascular endothelial cells can express programmed death-ligand 1 (PD-L1) and Fas ligand (FasL), selectively inhibit cytotoxic T cells (CTLs), and promote regulatory $\mathrm{T}$ cell (Treg) function to enhance the immunosuppressive TME $[9,10]$. It has been reported that many tumor angiogenic factors contribute to the immunosuppressive TME, including vascular endothelial growth factors, angiopoietin 2, placental growth factor, and transforming growth factor- $\beta$.

\section{Vascular endothelial growth factors}

As a critical factor in tumor angiogenesis, VEGFs could induce an immunosuppressive TME through hypoxia and a low pH [11]. VEGF can bind to VEGFR1 (FLT1) and prohibit dendritic cell (DC) maturation and antigen presentation [12], thus impeding $\mathrm{T}$ cell activation and limiting the adaptive antitumor immune response [13]. Increased peripheral VEGF levels are associated with decreased peripheral mature DCs, and anti-VEGF treatment could increase the number of mature DCs and reverse VEGF-mediated immunosuppression [14]. Elevated VEGF-A levels promote $\mathrm{CD}^{+} \mathrm{T}$ cell exhaustion by enhancing the expression of PD-1 [15] and contribute to Treg proliferation [16] and myeloid-derived suppressor cell (MDSC) accumulation [17] in the TME. However, Palazon et al. demonstrated that hypoxia and hypoxia-inducible factor- $1 \alpha$ (HIF- $1 \alpha)$ support the acquisition of an effector phenotype by $\mathrm{CD}^{+} \mathrm{T}$ cells, but the activated effector $\mathrm{CD} 8^{+} \mathrm{T}$ cells could produce high levels of VEGF-A [18]. The above results indicate that the regulation mechanism between VEGF and the TME immune status needs be further investigated.

In addition, VEGF-A induces thymocyte selectionassociated HMG-bOX (TOX)-mediated depletion of cytotoxic T lymphocytes (CTLs) [19]. TOX is a crucial transcription factor in $\mathrm{T}$ cell development and plays a vital role in T cell exhaustion [20]. VEGF-A upregulates the expression of TOX and initiates TOX-mediated reprogramming into an exhausted state in $\mathrm{CD}^{+} \mathrm{T}$ cells [19]. Knockout of VEGFR-2 downregulates TOX expression and reactivates tumor-specific exhausted $\mathrm{CD}^{+} \mathrm{T}$ cells, indicating the therapeutic potential of targeting the VEGF/VEGFR-2 axis [19].

\section{Angiopoietin 2}

Activated angiopoietin 2 (ANG2) upregulates adhesion molecule expression and recruits bone mesenchymal stem cells (BMSCs), Tregs, and M2-like macrophages expressing the ANG receptor (tyrosine kinase with Ig and EGF homology domains-2, TIE-2) [7, 21]. Additionally, ANG2 suppresses monocyte antitumor function by inhibiting TNF- $\alpha$ secretion [22] and promotes Treg activation and CTL inhibition through interleukin 10 (IL10) [23].

\section{Placental growth factor}

Placental growth factor (PlGF), as a member of the VEGF family that induces an angiogenic phenotype, directly interacts with VEGFR1 to stimulate tumor angiogenesis and promote macrophage repolarization into the M2-like phenotype, facilitating immune escape [24]. PIGF blockade induces vascular normalization and macrophage phenotypic polarization from an M2-like state to an M1-like state [25].

\section{Transforming growth factor- $\beta$}

Transforming growth factor- $\beta$ (TGF- $\beta$ ) is another important factor that regulates pericyte and endothelial cell proliferation and induces different angiogenic responses according to the balance between activin receptor-like kinase 1 (ALK1) and ALK5 signals. TGF- $\beta$ /ALK1 signaling promotes endothelial cell proliferation, migration and tube formation by activating SMAD1/5 [26]. In addition, TGF- $\beta$ inhibits natural killer (NK) cells and T cells to suppress tumor immune surveillance [27].

\section{TME elements in regulating tumor angiogenesis}

Tumor-infiltrating immune cells (TIICs) are deeply involved in the process of tumor angiogenesis, and immunosuppressive cells can promote antiangiogenic therapy resistance by inducing neovascularization in the TME [28, 29] (Fig. 1). Immune cells can secrete proangiogenic or antiangiogenic factors to directly affect the phenotype and function of the tumor vascular 


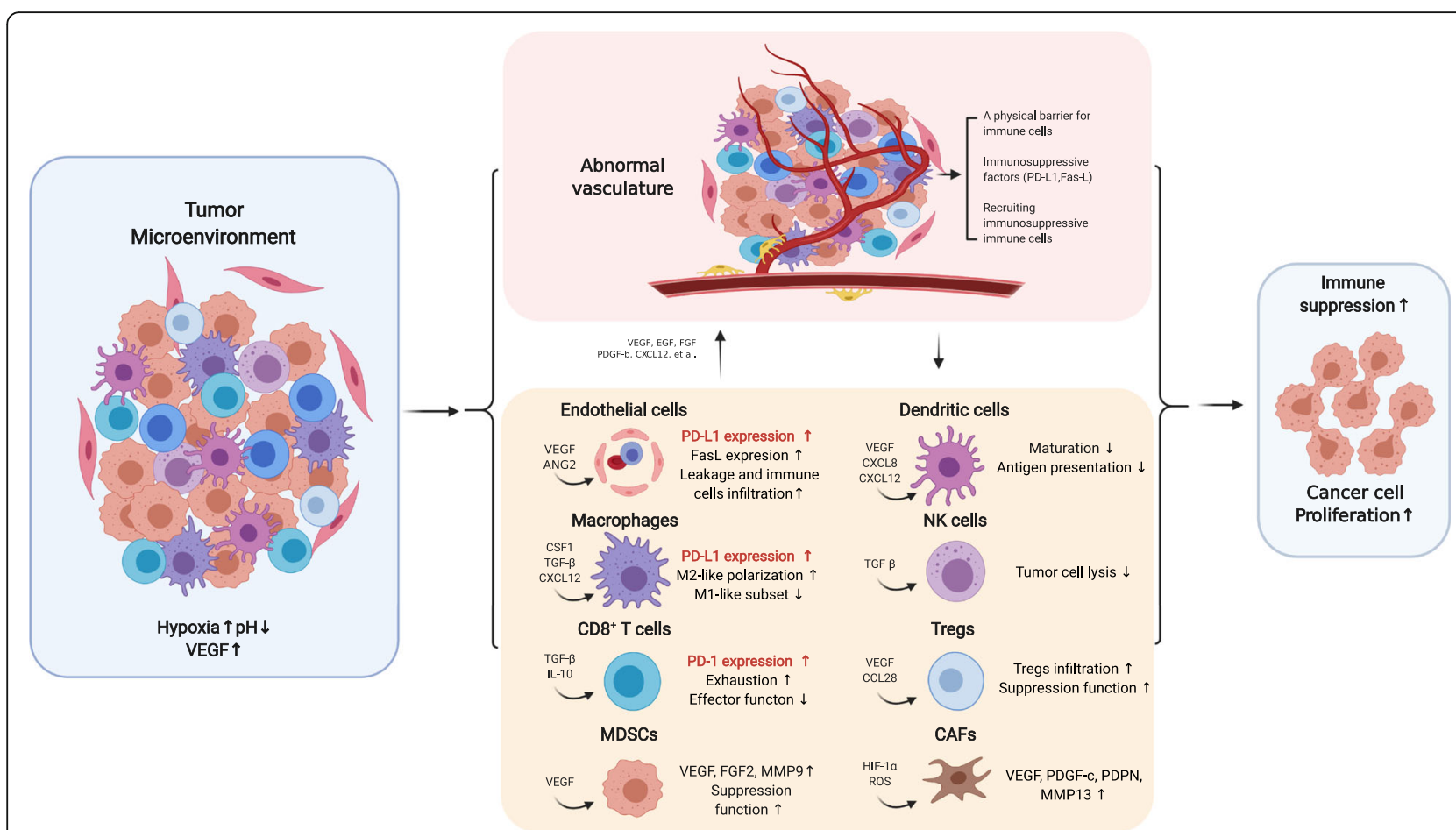

Fig. 1 Abnormal tumor vasculature triggers immunosuppression in the tumor microenvironment (created with BioRender.com). Malformed and dysfunctional vascular systems in breast cancer cause perfusion restriction, leading to hypoxia and acidosis in the TME. Tumor vasculature abnormalities promote immunosuppression through multiple mechanisms. VEGF induces tumor angiogenesis, and tumor vascular endothelial cells with PD-L1 and Fas-L expression recruit immunosuppressive cells. CSF1, TGF- $\beta$, and CXCL12 polarize TAMs from a protumorigenic M1-like phenotype into an antitumorigenic M2-like phenotype. VEGF, CXCL8, and CXCL12 inhibit DC maturation, resulting in impaired antigen presentation and leading to disrupted T cell activation. TGF- $\beta$ and IL-10 induce CD8 ${ }^{+}$T cell exhaustion, and TGF- $\beta$ inhibits NK cell function. Tregs and MDSCs accumulate, activate, and expand in the TME. The CAFs in the TME promote tumor angiogenesis by producing VEGF, PDGF-C, PDPN, and MMP13. The PD-L1 pathway is normally activated as a mechanism to evade the antitumor immune response. Overall, aberrant tumor angiogenesis results in an immunosuppressive TME. ANG2, Angiopoietin 2; CAFs, Cancer-associated fibroblast; CCL28, CC chemokine ligand 28; CXCL8, CXC chemokine ligand 8; CXCL12, CXC chemokine ligand 12; CSF1, Colony-stimulating factor 1; DC, Dendritic cell; Fas-L, FAS antigen ligand; FGF, Fibroblast growth factor; MMP, Matrix metallopeptidase; NK, Natural killer; PD-1, Programmed cell death protein 1; PD-L1, Programmed cell death 1 ligand 1; PDGF, Platelet-derived growth factor; PDPN, Podoplanin; ROS, Reactive oxygen species; TAM, Tumor-associated macrophage; TGF- $\beta$, Transforming growth factor beta; TME, Tumor microenvironment; Tregs, Regulatory T cells; VEGF, Vascular endothelial growth factor

endothelium [14, 30, 31] or transform into other immune cell types, which indirectly affects the quantity and quality of tumor blood vessels [32, 33].

\section{Macrophages}

In a clinical trial evaluating immunotherapy in triplenegative breast cancer (TNBC), the expression level of PD-L1 on tumor-associated macrophage (TAMs) was positively correlated with the response to immunotherapy, indicating the vital role of TAMs in the TME [34]. According to differences in functions and secreted cytokines, macrophages are divided into M1-like (antiangiogenic phenotype) and M2-like (proangiogenic phenotype) macrophages [35-37]. M1-like macrophages inhibit angiogenesis and induce vascular maturation by secreting antiangiogenic cytokines (IL-12 and TNF- $\alpha$ ) [38, 39]. M1-like macrophages secrete IL-12 to polarize other TAMs into the M1-like phenotype, further reducing the microvascular density through a positive feedback loop [39-41]. However, previous studies have demonstrated that M2-like macrophages are more dominant than M1-like macrophages in the TME [37, 39]. M2-like macrophages promote tumor angiogenesis by producing proangiogenic growth factors (VEGF-A, epidermal growth factor (EGF), and fibroblast growth factor (FGF)), proangiogenic CXC chemokines (CXCL8/IL-8 and CXCL12), and angiogenesis-related factors (TGF- $\beta$ and TNF- $\alpha$ ). These factors enhance the migration and proliferation of endothelial cells and polarize M1-like macrophages into an M2-like phenotype.

The success of antiangiogenic therapy is partly based on macrophage polarization from an M2-like to an M1like phenotype [42]. Eradication of macrophages with anti-colony stimulating factor 1 (CSF1) antibodies eliminates the benefits of antiangiogenic therapy, suggesting the importance of macrophages in antiangiogenic 
efficacy [43]. In mouse breast cancer models, elimination of macrophages with clodronate liposomes inhibited tumor angiogenesis and growth $[44,45]$.

TIE2-expressing macrophages (TEMs) are another unique subtype of TAMs with the capacity to promote tumor angiogenesis [43]. TEMs can bind to ANG2 secreted by endothelial cells or tumor cells and further enhance angiogenesis [46]. Targeted inhibition of TEMs has been indicated to induce tumor vascular normalization and promote tumor regression [47].

\section{Dendritic cells}

DCs, an essential adaptive immune component of the TME, regulate tumor angiogenesis in accordance with the maturation state. Mature DCs suppress tumor angiogenesis by secreting antiangiogenic cytokines (e.g., IL-12 and IL-18) [48, 49]. Moreover, mature DCs release interferon- $\alpha$ (IFN- $\alpha)$ to directly inhibit the proliferation of endothelial cells [50]. In the TME, tumor cells recruit immature DCs from the peripheral blood by releasing multiple cytokines (e.g., VEGF, $\beta$-defensin, CXCL12, HGF, and CXCL8), which lack the ability to inhibit tumor angiogenesis [14].

\section{$\mathrm{CD}^{+}$CTLs}

$\mathrm{CD}^{+}$CTLs play a key role in inhibiting tumor angiogenesis by secreting IFN- $\gamma[51,52]$, which directly inhibits endothelial cell proliferation and tumor vascularization [53] and polarizes M2-like TAMs to an M1-like phenotype [54]. IFN- $\gamma$ also enhances blood vessel maturation to promote tumor vascular remodeling and inhibit tumor growth by reducing VEGF-A levels and increasing CXCL9, CXCL10 and CXCL11 levels [55, 56].

\section{Th1, Th2 and Th17 cells}

$\mathrm{CD}^{+}{ }^{+} \mathrm{T}$ helper 1 (Th1) cells help normalize tumor vessels by producing IFN- $\gamma$ in the TME. In a breast cancer model, Th1 cell activation was shown to improve pericyte coverage, reduce abnormal hyperplasia of tumor vessels, and induce vascular normalization $[57,58]$. Th1 cells also inhibit tumor angiogenesis by polarizing M2like TAMs into M1-like macrophages and inducing DC maturation $[8,59]$. Unlike Th1 cells, Th2 cells recruit M2-like macrophages to promote tumor angiogenesis by expressing IL-4, IL-5 and IL-13 [32, 41, 60]. Th17 cells, another subtype of $\mathrm{CD}^{+}{ }^{+} \mathrm{T}$ helper cells, promote endothelial cell proliferation and tumor angiogenesis by expressing IL-17, a poor prognostic factor in breast cancer $[61,62]$.

\section{Tregs}

Hypoxic conditions in the TME contribute to Treg proliferation by CCL28 and VEGF overexpression in tumor cells [63, 64]. Tregs secrete VEGF, recruit endothelial cells and promote tumor angiogenesis directly [65]. Furthermore, Tregs indirectly facilitate tumor angiogenesis by inhibiting Th1 cell activation and polarizing TAMs into the M2-like phenotype [35, 41]. Targeted removal of Tregs reduces VEGF levels and inhibits tumor angiogenesis in the TME [66].

\section{MDSCs}

In the TME, MDSCs promote tumor angiogenesis by producing VEGF, FGF2, Bv8, and matrix metalloproteinase (MMP9) $[67,68]$. CD11 $\mathrm{b}^{+} \mathrm{Gr}^{+}$MDSCs increase intratumor vascular density and reduce tumor necrosis [69, 70]. In addition, MDSCs can be directly involved in tumor angiogenesis by acquiring endothelial cell properties $[69,71]$. Reduced MDSCs in the TME are associated with reduced tumor angiogenesis and tumor growth inhibition [72, 73]. Several studies have linked the accumulation of MDSCs to an increase in intratumor VEGF concentrations during disease progression [74]. VEGF stimulates the recruitment of MDSCs, promoting immunosuppression and angiogenesis [75, 76]. MDSCs overcome VEGF inhibition by secreting large amounts of VEGF or interfere with the effects of VEGF-targeted therapy by activating the VEGF-independent proangiogenic signaling pathway [77].

\section{Cancer-associated fibroblasts (CAFs)}

CAFs account for $50-90 \%$ of solid tumors and have complex interactions with tumor cells and the extracellular matrix (ECM) [78, 79]. In breast cancer, CAFs secrete stromal cell-derived factor-1 (SDF1), CXC chemokine 12 (CXC12) and VEGF to promote angiogenesis [80-82]. In addition, CAFs secrete podoplanin (PDPN), which can stimulate angiogenesis and lymphangiogenesis by upregulating VEGF-C but not VEGF-A in breast cancer [83-85]. Galectin-1 derived from CAFs accelerates angiogenesis and promotes tumor invasion by enhancing VEGF expression in tumor cells and VEGFR2 phosphorylation in epithelial cells (ECs) [86-89]. In the hypoxic TME of breast cancer, G-protein-coupled estrogen receptor (GPER), HIF- $1 \alpha$ and reactive oxygen species (ROS) are involved in CAF activation and VEGF expression upregulation to promote hypoxia-dependent tumor angiogenesis [90, 91]. CAFs can release ECM-bound VEGF by secreting MMP-13 [92]. CAFs also promote tumor angiogenesis in a VEGF-independent manner. In chemotherapy-resistant tumors, increased expression of platelet-derived growth factor-c (PDGF-c) by CAFs contributes to tumor angiogenesis during antiVEGF therapy [93]. 


\section{Antiangiogenic therapy reverses the immunosuppressive TME}

Antiangiogenic therapy promotes TIIC accumulation

Antiangiogenic therapy could normalize tumor vessels by pruning immature vessels [94], provides paths for immune cell infiltration and recruits effector TIICs [95]. Firstly, antiangiogenic treatment has been identified to induce DC maturation and promote antigen presentation $[18,96]$. Secondly, it upregulates the expression of adhesion molecules (e.g., intercellular adhesion molecule-1 (ICAM1) and vascular cell adhesion molecule-1 (VCAM1)) during the vascular normalization window and helps $\mathrm{T}$ cells cross the endothelial barrier and promote $\mathrm{CD}^{+} \mathrm{T}$ cell accumulation [7, 97]. Thirdly, it transforms M2-like TAMs into the M1 phenotype [98]. Meanwhile, antiangiogenic therapy reduces the levels of immunosuppressive TIICs including Tregs and MDSCs in peripheral blood, accompanied by an improvement in the Th1 cell response [99]. High endothelial venules (HEVs) are specialized vascular units organized in tertiary lymphoid structures that recruit immature $\mathrm{T}$ cells and help immature $\mathrm{T}$ cells differentiate into CTLs [100]. Endothelial cells in HEVs support the homing and migration of effector immune cells into the tumor via ICAM1 [101]. HEVs are remodeled by VEGF$\mathrm{D}$ in tumor tissues, expand and lose their typical morphology and lymphocyte transport-related molecular features (loss of CCL21 expression) [102-104]. Antiangiogenic therapy helps restore the typical morphology of HEVs and promotes lymphatic drainage [100]. Antiangiogenic therapy also upregulates PD-L1 expression on endothelial cells and tumor cells in mouse breast cancer models $[9,101]$, which sensitizes the tumor cells to anti-PD-1 therapy [7].

\section{High dose or low dose?}

High-dose or long-term antiangiogenic therapy causes large-scale vascular pruning in vitro, which aggravates hypoxia or acidosis in the TME and promotes immunosuppression, suggesting that the optimal doses of antiangiogenic drugs need to be further explored [105, 106]. When excessive vessels are overpruned or alternative angiogenic pathways are activated, the window of vascular normalization could close [107]. In a study of a hepatocellular carcinoma model, blocking VEGF signaling with high-dose sorafenib aggravated TME hypoxia and promoted the recruitment of immunosuppressive Tregs and M2-like macrophages [7]. In addition, excessive antiangiogenic therapy could produce a hypoxic environment that favors cancer stem cell survival [108]. In contrast, lower doses of antiangiogenic agents are likely to maintain long-term vascular normalization [2]. The antitumor activities of TIICs could be improved by normalizing vessels, reducing tumor hypoxia, and restoring the physiological $\mathrm{pH}$ [109]. Hence, to realize the full potential of antiangiogenic therapy, the antiangiogenic regimen and dose need to be adjusted according to the baseline level of the microvascular density (MVD) and pretreatment level of circulating VEGF [110, $111]$.

\section{Mono-blockade or dual-blockade?}

Antiangiogenic therapy could create a vascular normalization window and improve the delivery of therapeutic drugs and effector immune cells [112]. The process of vascular normalization is short and reversible, and the normalization window is typically short (from weeks to months), depending on the type and dose of antiangiogenic agent $[7,113]$. Tumors can evade antiangiogenic therapy through upregulation of alternative angiogenic pathways (e.g., ANG2/TIE2 signaling) [42, 43]. In melanoma, peripheral ANG2 levels represent an effective predictor of ICB immunotherapy response with increased ANG2 levels indicating no response to ICB immunotherapy [114]. Compared with anti-VEGF or anti-ANG2 monotherapy, dual blockade of VEGF and ANG2 relieves TME immunosuppression [43] and prolongs the vascular normalization window [115] and overall survival (OS) in preclinical studies [9, 116, 117]. Furthermore, the dual blockade of VEGF and ANG2 promotes the accumulation of $\mathrm{CD}^{+}$and $\mathrm{CD}^{+} \mathrm{T}$ cells and increases IFN- $\gamma$ levels in the TME [9, 117]. However, it is crucial to select the proper doses for dual antiangiogenic therapy to avoid excessive vascular pruning and increase the delivery of chemotherapeutic drugs [118]. Therefore, targeting VEGF and ANG2 simultaneously improves the efficacy of antiangiogenic therapy and promotes the restoration of antitumor immunity in the TME.

\section{Immunotherapy promotes vascular normalization}

Immunotherapy normalizes vessels in various tumor models, and vascular normalization is attributed to the accumulation and increased antitumor activities of Th1 cells in breast cancer $[7,100]$. In CD4+ T cell-deficient mouse mammary tumor models, pericyte coverage of blood vessels was reduced, and tumor tissue hypoxia was increased, suggesting that CD4+ $\mathrm{T}$ cell deficiency led to vascular abnormalities [57]. ICB activates CD4+ and CD8+ T cells in the TME, remodels the tumor vasculature, and indirectly enhances their antitumor activity [30]. The accumulation and reactivation of effector $\mathrm{T}$ cells in the TME subsequently helps long-term tumor control indirectly [119]. In addition, tumor tissue hypoxia leads to an increase in Tregs $[66,120,121]$. Tregs promote tumor angiogenesis, and the depletion of Tregs activates CD8+ $\mathrm{T}$ cells and promotes vascular normalization $[66,122]$. Understanding the vascular 
normalization function of ICB immunotherapy is helpful to optimize the administration sequence of ICB and antiangiogenic agents to expand the window of normalization and extend the survival time of breast cancer patients [123].

As a new target of immunotherapy, stimulator of interferon gene (STING) has been associated with tumor vascular system regulation and has shown a synergistic effect with anti-VEGF2 antibodies and ICB [52]. Activated STING signaling inhibits tumor angiogenesis and induces vascular normalization through activation of type I IFN signaling [14]. Intriguingly, $\mathrm{CD} 8^{+} \mathrm{CTLs}$ are implicated in vascular remodeling triggered by STING signaling. STING agonists and anti-VEGF2 antibodies synergistically promote vascular normalization and prolong antitumor immunity [14]. It is worth noting that STING-based immunotherapy is effective in overcoming antiangiogenic therapy or ICB monotherapy resistance [52]. Thus, the tumor vascular normalization effects of immunotherapy provide a new understanding of tumor vascular remodeling and immune reprogramming. Nevertheless, the conditions required for immunotherapy-induced vascular normalization, the duration of the response, and the distinction from antiangiogenic therapy-mediated vascular normalization remain unclear $[30,119]$.

\section{The influence of tumor MHC-I expression}

To avoid recognition by CD8+ T cells, tumor cells have adopted an immune evasion strategy of loss of MHC I expression [124-127]. The majority of early-stage tumors are MHC-I positive [128]. Tumor-resistant CD8+ $\mathrm{T}$ cells exert evolutionary selection pressure on tumor MHC-I-positive cells, resulting in defective or negative MHC-I expression in tumors $[129,130]$. A study showed that deletion of MHC-I expression was associated with resistance to ICB immunotherapy [131]. The low MHCI expression hides tumor mutation neoantigens, which explains why some tumors (even with high TMB) do not respond to ICB [132]. Furthermore, during immunotherapy (interferon- $\alpha /$ autologous vaccination), metastases with high MHC-I expression were regressive, whereas metastases with low MHC-I expression were progressive [130].

Antiangiogenic therapy potentially represents an optional approach to overcome MHC-I low expression tumors with immunotherapy resistance. Wallin et al. demonstrated that the combination of bevacizumab and atezumab for metastatic renal cell carcinoma promoted antigen-specific $\mathrm{T}$ cell migration and elevated intratumor MHC-I, Th1 and T effector cell markers and chemokines (most notably CX3CL1) [133]. In addition, antiangiogenic therapy normalizes tumor vasculature by reducing microvessel density and improving pericyte coverage, avoiding the influence of tumor MHC-I expression. Therefore, it is necessary to design prospective clinical trials to explore the antitumor effects of antiangiogenic therapy on tumors with low MHC-I expression.

\section{Antiangiogenic plus immunotherapy promotes TME normalization}

Antiangiogenic therapy and immunotherapy in different molecular subtypes of breast cancer

Previous literature suggests that microvascular density (MVD) levels are higher in TNBC than in other breast cancer subtypes [134] and that angiogenesis in TNBC is increased $[135,136]$. In neoadjuvant chemotherapy, the addition of bevacizumab improved the $\mathrm{pCR}$ rate in TNBC patients [137-139]. In metastatic TNBC patients, chemotherapy combined with bevacizumab improved progression-free survival (PFS) [140-143]. However, adding bevacizumab to chemotherapy resulted in an increased incidence of adverse events and did not improve overall survival in patients with metastatic TNBC [144]. In adjuvant chemotherapy, chemotherapy combined with bevacizumab did not improve invasive disease-free survival (iDFS) or OS in TNBC patients [145]. In summary, the addition of anti-vascular therapy to TNBC treatment may improve the clinical response, but there is no clinical evidence for improvement in OS. The clinical benefit of antiangiogenic monotherapy in TNBC remains controversial, and the therapeutic effects of multitarget tyrosine kinase inhibitors (TKIs) need to be further evaluated [146]. In the luminal or HER2enriched subtype of breast cancer, anti-HER2 trastuzumab and metronomic chemotherapy could also induce vascular normalization by upregulating the expression of thrombospondin-1 (THBS1) in breast cancer $[147,148]$. Similarly, cyclin-dependent kinase 4 (CDK4) and CDK6 inhibitors could enhance the efficacy of immunotherapy through vascular normalization [149].

Recently, most studies of ICB immunotherapy in breast cancer have focused on TNBC. Based on the positive results of the IMpassion130 trial, atezolizumab combined with paclitaxel was approved by the FDA for firstline treatment of inoperable locally advanced or metastatic PD-L1 ${ }^{+}$TNBC [3]. The KEYNOTE-355 trial was a randomized, double-blind, phase III trial that evaluated pembrolizumab plus chemotherapy (albumin-bound paclitaxel, paclitaxel or gemcitabine/carboplatin) as a first-line treatment for locally advanced or metastatic TNBC. The primary endpoint of progression-free survival (PFS) was achieved in PD-L1 $1^{+}$patients with a combined positive score (CPS) $\geq 10$ [150]. Compared with those for immunotherapy in advanced breast cancer, the results for immunotherapy in the neoadjuvant setting are more encouraging. In the phase II I-SPY2 trial, the pathological complete response (pCR) rate was increased 
by $38 \%$ ( 22 to $60 \%$ ) by the addition of pembrolizumab. This result might be attributed to the immunostimulatory effect of anthracyclines, which boosts intratumoral immunity and antigen presentation [151]. The phase II GeparNeuvo study showed an increased pCR rate in the durvalumab-pretreated group $(61.0 \%$ vs. $41.4 \%)$ [152, 153]. In the phase III KEYNOTE-522 trial, the addition of pembrolizumab to neoadjuvant chemotherapy increased the $\mathrm{pCR}$ rate of patients with early TNBC ( $64.8 \%$ vs. $51.2 \%)$, and pembrolizumab immunotherapy extended event-free survival (EFS) by 18 months (HR 0.63; 95\% CI 0.43-0.93) [154]. Immunotherapy is more effective in the neoadjuvant phase, which may be due to better PD-L1 positivity rates being found in neoadjuvant patients with better baseline levels and physical status compared with advanced breast cancer patients.

\section{The exploration of antiangiogenic plus immunotherapy}

Studies have been designed to study the feasibility and function of antiangiogenic plus immunotherapy $(\mathrm{A}+\mathrm{I})$ combined therapy in TME normalization (Fig. 2). In unresectable hepatocellular carcinoma, compared with sorafenib, atezolizumab in combination with bevacizumab reduced mortality (HR 0.58 ; $95 \%$ CI $0.42-0.79$; $P<$ $0.001)$ and improved overall survival (67.2\% vs $54.6 \%)$ [155]. In metastatic non-squamous non-small cell lung cancer, the addition of atezolizumab to bevacizumab combination chemotherapy significantly improved overall survival (19.2 vs. 14.7 months; HR 0.78; 95\% CI 0.64 to $0.96 ; P=0.02$ ) [156]. In addition, PD-L1 expression in tumor tissue could not serve as a biomarker to predict the response to A + I combination therapy [156]. In advanced renal cell carcinoma, compared with sunitinib, treatment with axitinib combined with pembrolizumab [157] or with alvumab [158] increased progression-free survival. In advanced endometrial cancer, lenvatinib plus pembrolizumab showed good antitumor activity [159]. In breast cancer, immunotherapy was administered to patients who received first-line bevacizumab to determine whether ICB could restore sensitivity to

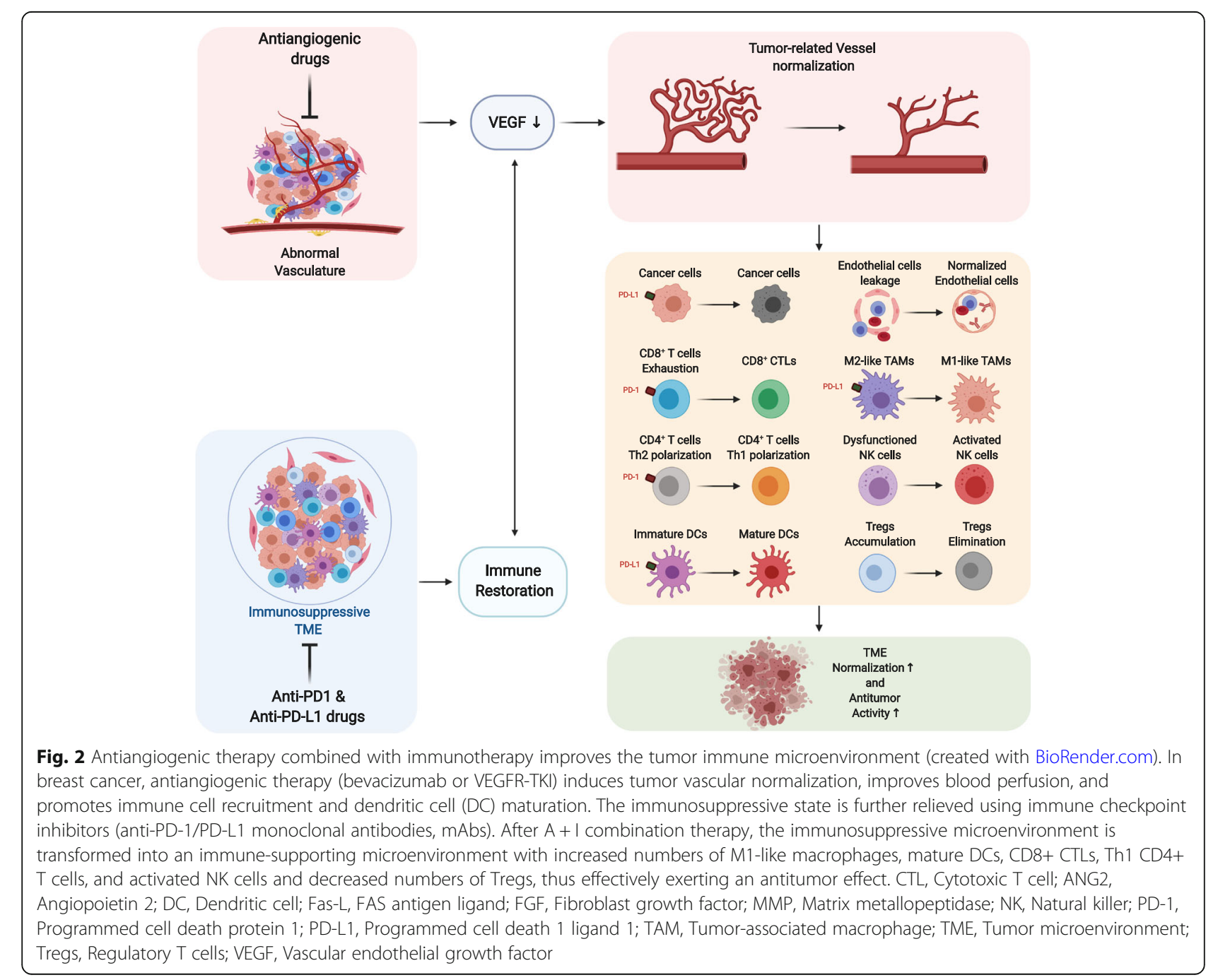


antiangiogenic agents. A recently published phase $\mathrm{Ib}$ study recruited patients with metastatic HER2-negative breast cancer who had progressed after at least 6 weeks of first-line treatment with bevacizumab, and these patients were treated with durvalumab plus bevacizumab $[160,161]$. Interestingly, the patients whose disease remained stable at the first evaluation (2 months) showed a 1.2 - to 3.5 -fold increase in $\mathrm{CD}^{+}$effector memory $\mathrm{T}$ cell levels in the peripheral blood, but no such change was observed in patients with disease progression $[160,161]$. The benefits of antiangiogenic drugs are time and dose dependent, and determining the window of normalization of tumors is challenging [119]. Clinical trials have shown that the combination of lowdose regorafenib with nivolumab is superior to highdose therapy in advanced gastric or colorectal cancer [162], suggesting that the administration of immunotherapy with antiangiogenic therapy protects against excessive pruning of blood vessels [163]. Further studies are needed to investigate the clinical benefits of $\mathrm{A}+\mathrm{I}$ combination therapy in breast cancer, especially for TNBC [164].

\section{Antiangiogenic therapy reduces the adverse events of ICB immunotherapy}

Most adverse events related to immunotherapy are linked with a hyperactive immune response, such as $\mathrm{T}$ cell-mediated autoimmune inflammation and immune homeostasis disorder, which may lead to immunerelated damage to normal tissues, including the gastrointestinal tract, skin and liver. These adverse events could be alleviated by interrupting or reducing the dose of ICB immunotherapy [165]. Considering that vascular normalization could improve the delivery of therapeutic drugs, the proposed combination strategy may require lower doses of ICB to enhance immune responses while reducing the risk of adverse effects [7]. Notably, ICB immunotherapy increases the risk of brain edema, occasionally leading to death [166]. In contrast, antiangiogenic drugs could reduce brain edema, providing theoretical support for combined low-dose antiangiogenic therapy and immunotherapy in the treatment of brain metastases [167]. Based on current clinical data, some ICB agents (e.g., SHR-1210) could cause reactive capillary hemangioma [168], whereas antiangiogenic therapy could suppress hemangioma and reduce antiPD-1-related adverse effects [169]. For antiangiogenic therapy, the common adverse effects include hypertension, hemorrhage, thrombosis, and proteinuria. Breast cancer is a type of tumor with connective tissue hyperplasia, and increases in the levels of extracellular matrix molecules (including type I collagen and hyaluronan) compress vessels and lead to hypoxic conditions. Angiotensin receptor blockers (ARBs) normalize the matrix and decompress vessels, reducing the adverse effects of antiangiogenic therapy [170]. In addition, ARBs activate both the innate and adaptive immune systems [171] and might improve the effects of $\mathrm{A}+\mathrm{I}$ combination therapy $[172,173]$.

\section{Serum-based biomarkers}

A + I combination therapy improves the tumor tissue perfusion status and activates the local immune response; therefore, it is of clinical importance to identify relevant biomarkers reflecting the vascular-immune status in the TME. Serum biomarkers, which have previously been used to monitor response to antiangiogenic therapies [174, 175], could be explored for predicting response to antiangiogenic combination immunotherapy. Serum ANG2, a key factor in vascular maturation [176], was negatively associated with clinical response rates and overall survival to anti-CTLA4 immunotherapy in melanoma [114]. In tumor vaccine-treated NSCLC patients, ANG2 and VEGF-A serum levels could be predictive factors for long-term remission and survival [30]. Together, these findings support a correlation between tumor vascular remodeling and antitumor immune response generation, suggesting a potential role for the use of vascular-related biomarkers to predict clinical response to anti-vascular combination immunotherapy. However, serum-based biomarkers are disturbed by the host physical status, and whether they truly reflect the status of the TME requires further investigation. In addition, whether novel serum biomarkers, such as exosomes, circulating tumor DNA (ctDNA), serum RNA, immune cell subpopulation counts and lactate dehydrogenase (LDH) levels, have clinical predictive significance deserves further exploration.

\section{Tissue-based biomarker}

The main limitation of tissue-based biomarkers is the need for repeat biopsies. In metastatic breast cancer, tumor tissue PD-L1 expression and tumor mutational burden (TMB) could be predictors of immunotherapy efficacy $[3,7]$. In contrast, for breast cancer neoadjuvant treatment, predictors of immunotherapy efficacy still need to be further explored [153]. Mpekris et al. investigated the complex interactions among tumor cells, immune cells (M1/M2-like TAMs, NK cells, CD4+ / CD8+ $\mathrm{T}$ cells, and Tregs), and endothelial cells and developed a mathematical model for tumor tissue perfusion assessment and immunotherapy efficacy prediction [119]. The model was designed considering the levels of proangiogenic molecules (e.g., ANG1, ANG2, PDGF-b, VEGF and CXCL12) in the TME and the vascular normalization effect of CD4+ and CD8+ T cells [119]. The model predictions exhibit good correlation with the 
preclinical results, which need further validation in prospective clinical studies.

The efficacy of immunotherapy depends on tumor perfusion, and any approach to improve perfusion could simultaneously enhance immunotherapy. The incidence of HEVs in tumors might also predict the effect of $\mathrm{A}+\mathrm{I}$ combination therapy [146]. The formation of HEVs has been demonstrated to improve the effects of ICB immunotherapy [177]. In breast cancer models, HEV formation was mediated by lymphotoxin- $\beta$ receptor (LT- $\beta R$ ) signal transduction. Treatment with an agonistic LT- $\beta$ R antibody induced HEV development and increased CTL activation, further enhancing the efficacy of antiangiogenic therapy [101].

In addition, functional measurements of vascular changes by noninvasive measures, such as dynamic contrast enhanced (DCE) MRI [178], dynamic optical breast imaging (DOBI) [179], and shear-wave elastography (SWE) [180], might be helpful in A + I combination therapy. These functional measurements could provide important information about the TME status and allow dynamic monitoring during treatment. The biomarkers and cells described above in the breast cancer TME are summarized in Table 1.

\section{Prospects of antiangiogenic therapies in breast cancer} To verify clinical efficacy, several clinical trials using different combinations of antiangiogenic therapies and immunotherapies have been conducted (Table 2). According to the Clinicaltrials.gov registry, most ongoing clinical trials (9/11) focus on patients with advanced breast cancer, whereas $2 / 11$ trials focus on the use of antiangiogenic therapy and immunotherapy in the neoadjuvant phase.

Due to the narrow window of antiangiogenic therapy and the low positivity rate of PD-L1 in patients with advanced breast cancer, the combined use of antiangiogenic therapy and immunotherapy in earlystage breast cancer may produce better clinical benefits. Combining antiangiogenic therapy and immunotherapy may be more promising in the neoadjuvant setting, whereas the timing of antiangiogenic therapy and surgery should also be considered. In addition, current combined antiangiogenic treatments mainly focus on monoclonal antibodies (e.g., bevacizumab). Investigating the effects of multitarget TKIs in combination with immunotherapy is also needed in future clinical trials.

Table 1 Biomarkers and cells in the breast cancer microenvironment

\begin{tabular}{|c|c|}
\hline TME elements & Function \\
\hline M1-like TAMs & Suppress angiogenesis (IL-12 and TNF-a); Induce vascular maturation \\
\hline M2-like TAMs & $\begin{array}{l}\text { Promote angiogenesis (VEGF-A, EGF and FGF); Enhance ECs migration and proliferation; Polarize M1-like into M2- } \\
\text { like TAMs }\end{array}$ \\
\hline Mature dendritic cells & Suppress angiogenesis (IL-12 and IL-18); inhibit EC proliferation \\
\hline Immature dendritic cells & Lack the ability to inhibit angiogenesis \\
\hline CD8+ CTLs & Suppress angiogenesis (IFN- $\gamma)$ \\
\hline Th1 cells & Suppress angiogenesis (IFN- $\gamma)$; improve pericyte coverage \\
\hline Th2 cells & Promote angiogenesis (IL-4, IL-5 and IL-13); recruit M2-like TAMs \\
\hline Th17 cells & Promote angiogenesis (IL-17); promote ECs proliferation \\
\hline Tregs & Promote angiogenesis (VEGF); inhibit Th1 cell activation; promote M2-like TAMs \\
\hline MDSCs & Promote angiogenesis (VEGF, FGF2, BV8 and MMP9); acquire endothelial cell properties \\
\hline CAFs & $\begin{array}{l}\text { Promote angiogenesis (VEGF, CXC12, SDF1 and PDGF-C); enhance VEGF expression (PDPN and LGALS1); release } \\
\text { ECM-bound VEGF }\end{array}$ \\
\hline Serum-based biomarkers & Function \\
\hline ANG2 and VEGF-A & Key factor of angiogenesis; predict long-term remission and survival \\
\hline Tissue-based biomarkers & Function \\
\hline HEVs & $\begin{array}{l}\text { Specialized vascular units organized in tertiary lymphoid structures; help immature T cells differentiate into CTLs; } \\
\text { the formation of HEVs indicates the improvement of ICB immunotherapy efficacy }\end{array}$ \\
\hline TME model & $\begin{array}{l}\text { Investigate the complex interactions between tumor cells, immune cells (M1/M2-like TAMs, NK cells, CD4 }{ }^{+} \text {/ CD8 }{ }^{+} \\
T \text { cells, and Tregs), and endothelial cells; assess tissue perfusion and predict immunotherapy efficacy }\end{array}$ \\
\hline $\begin{array}{l}\text { Noninvasive measures (DCE-MRI, } \\
\text { DOBI, SWE) }\end{array}$ & Measure vascular changes and provide information on TME status \\
\hline
\end{tabular}


Table 2 Currently enrolled clinical studies of antiangiogenic immunotherapy combinations for breast cancer (data source: clinicalTrials.gov, Oct 2020)

\begin{tabular}{|c|c|c|c|c|c|}
\hline No & Title & Status & Conditions & Interventions & Locations \\
\hline 1 & $\begin{array}{l}\text { A Study to Describe the Diagnosis, Anti- } \\
\text { Cancer Treatment and Clinical Outcome } \\
\text { in Patients with Newly Diagnosed } \\
\text { Breast Cancer in Latin America }\end{array}$ & Recruiting & Breast Cancer & $\begin{array}{l}\text { Drug: Bevacizumab, Drug: Trastuzumab, } \\
\text { Drug: Ado-trastuzumab emtansine, } \\
\text { Drug: Pertuzumab, Drug: Atezolizumab, } \\
\text { Drug: Capecitabine }\end{array}$ & $\begin{array}{l}\text { Instituto Alexander Fleming, } \\
\text { Buenos Aires, Argentina, and } \\
\text { more }\end{array}$ \\
\hline 2 & $\begin{array}{l}\text { A Multi-cohort Phase II Study of HER2- } \\
\text { positive and Triple- negative Breast Can- } \\
\text { cer Brain Metastases. }\end{array}$ & $\begin{array}{l}\text { Not yet } \\
\text { recruiting }\end{array}$ & Breast Cancer & $\begin{array}{l}\text { Drug: Pyrotinib, Drug: Temozolomide } \\
\text { Injection, Drug: SHR-1316 (PD-L1), Drug: } \\
\text { Bevacizumab, Drug: Cisplatin/ } \\
\text { Carboplatin }\end{array}$ & $\begin{array}{l}\text { Fudan University Shanghai } \\
\text { Cancer Center }\end{array}$ \\
\hline
\end{tabular}

3 Pre-operative Immunotherapy Combination Strategies in Breast Cancer

4 Safety and Efficacy of Toripalimab in HER2- Metastatic Breast Cancer Patients Treated with Metronomic Vinorelbine

5 SAFIR02_Breast - Efficacy of Genome Analysis as a Therapeutic Decision Tool for Patients with Metastatic Breast Cancer

6 A Study Evaluating the Efficacy and Safety of Multiple ImmunotherapyBased Treatment Combinations in Patients with Metastatic or Inoperable Locally Advanced Triple- Negative Breast Cancer

7 QUILT-3.067: NANT Triple Negative Breast Cancer (TNBC) Vaccine: Molecularly Informed Integrated Immunotherapy in Subjects with TNBC Who Have Progressed on or After Standard-of-care Therapy.

8 A Study of Multiple ImmunotherapyBased Treatment Combinations in Hormone Receptor (HR)-Positive Human Epidermal Growth Factor Receptor 2 (HER2)-Negative Breast Cancer

9 Evaluation of IPI-549 Combined with Front-line Treatments in Pts. With TripleNegative Breast Cancer or Renal Cell Carcinoma (MARIO-3)

10 I-SPY 2 TRIAL: Neoadjuvant and Treat Breast Cancer
Recruiting Breast Cancer, Drug: Atezolizumab, Drug: Cobimetinib, Estrogen Receptorpositive Breast Cancer

Recruiting Metastatic Breast Drug: Vinorelbine $40 \mathrm{mg}$, Biological: Cancer
Barts Health NHS Trust, London, United Kingdom

Cancer Hospital, Chinese Academy of Medical Sciences, Beijing, Beijing, China, and more Bevacizumab $15 \mathrm{mg} / \mathrm{kg}$, Drug: Cyclophosphamide $50 \mathrm{mg}$, Drug: Capecitabine $500 \mathrm{Mg}$ Oral Tablet, Drug: Cisplatin, Radiation: Hypofractionated radiotherapy

Active, Metastatic Breast Drug: AZD2014, Drug: AZD4547, Drug: not Cancer AZD5363, Drug: AZD8931, Drug: recruiting MEDI4736, Drug: Anthracyclines, Drug: Taxanes, and 12 more

Recruiting Triple-negative Breast Cancer

Active, Triple-negative not Breast Cancer recruiting

Drug: Capecitabine, Drug: Atezolizumab, Drug: Ipatasertib, Drug: SGN-LIV1A, Drug: Bevacizumab, Drug: Chemotherapy (Gemcitabine + Carboplatin or Eribulin), Drug: Selicrelumab, Drug: Tocilizumab, Drug: Nab-Paclitaxel, Drug: Sacituzumab Govitecould

Drug: Aldoxorubicin $\mathrm{HCl}$, Biological: N803, Biological: ETBX-011, Biological: ETBX-051, Biological: ETBX-061, Biological: GI-4000, Biological: GI-6207, Biological: GI-6301, Biological: haNK for Infusion, Biological: avelumab, and 8 more

Recruiting Breast Neoplasms

Drug: Atezolizumab, Drug: Bevacizumab, Drug: Entinostat, Drug: Exemestane, Drug: Fulvestrant, Drug: Ipatasertib, Drug: Tamoxifen, Drug: Abemaciclib
Institut de Couldcérologie de I'Ouest/Paul Papin, Angers, France, and more

University of California San Diego Medical Center; Moores Cancer Center, La Jolla, California, United States, and more

Chan Soon-Shiong Institute for Medicine, El Segundo, California, United States

University of Alabama at Birmingham, Birmingham, Alabama, United States, and more

Research Center, Chandler, Arizona, United States, and more

University of Alabama at Birmingham, Birmingham, Alabama, United States, and more

Research Site, Newnan, Georgia, United States, and more Personalized Adaptive Novel Agents to

Recruiting Breast Cancer Renal Cell Carcinoma

Recruiting Breast Neoplasms, Breast Cancer, Breast Tumors, Angiosarcoma $\begin{array}{lll}\text { Active, } & \text { Ovarian, Breast, } & \text { Drug: Olaparib, Drug: MEDI4736, Drug: } \\ \text { not } & \text { SCLC, Gastric } & \text { Bevacizumab }\end{array}$ recruiting Cancers

Drug: IPI-549, Drug: Atezolizumab, Drug: Ironwood Cancer and nab-paclitaxel, Drug: Bevacizumab

Drug: Standard Therapy, Drug: AMG 386 with or without Trastuzumab, Drug: AMG 479 (Ganitumab) plus Metformin, Drug: MK-2206 with or without Trastuzumab, Drug: AMG 386 and Trastuzumab, Drug: T-DM1 and Pertuzumab, Drug: Pertuzumab and Trastuzumab, Drug: Ganetespib, Drug: ABT-888, Drug: Neratinib, and 11 more

11 A Phase I/II Study of MEDI4736 in Combination with Olaparib in Patients With Advanced Solid Tumors. 


\section{Conclusion}

Antiangiogenic therapies normalize tumor vasculature, improve tissue perfusion, and promote the aggregation of TIICs in the TME. This mechanism forms the basis for combining antiangiogenic therapy with immunotherapy. With the advancement of preclinical and clinical studies, persuasive evidence supports that A + I combination therapy could reverse the immunosuppressive TME and yield overall prognostic improvement for breast cancer patients. However, A + I combination therapy has complex biological effects that might increase the risk of hemorrhage, hypertension, and immunerelated adverse effects. A considerable number of clinical trials are currently underway to determine whether A + I combination therapy promotes TME normalization and improves breast cancer survival, especially for TNBC. Given the high cost and side effects of $\mathrm{A}+\mathrm{I}$ combination therapy, further investigation on relevant biomarkers for A + I combination therapy, especially serum-based biomarkers and tissue-based noninvasive measurements for TME status detection, is needed.

\begin{abstract}
Abbreviations
ALK: Activin receptor-like kinase; ANG2: Angiopoietin 2; ARB: Angiotensin receptor blocker; BMSC: Bone mesenchymal stem cell; CAFs: Cancerassociated fibroblast; CCL28: CC chemokine ligand 28; CDK: Cyclindependent kinase; CPS: Combined positive score; CSF1: Colony stimulating factor 1; CTL: Cytotoxic T lymphocyte; CXC12: CXC chemokine 12; CXCL8: CXC chemokine ligand 8; CXCL12: CXC chemokine ligand 12; DC: Dendritic cell; DCE: Dynamic contrast enhanced; DOBI: Dynamic optical breast imaging; EC: Epithelial cell; ECM: Extracellular matrix; EFS: Event-free survival; EGF: Epidermal growth factor; FasL: Fas ligand; FGF: Fibroblast growth factor; FLT1: Fms Related Receptor Tyrosine Kinase 1; GPER: Gprotein-coupled estrogen receptor; HEV: High endothelial venule; HIF1a: Hypoxia-inducible factor-1a; HR: Hazard ratio; ICAM1: Intercellular adhesion molecule-1; ICB: Immune checkpoint blockade; iDFS: Invasive disease-free survival; IL: Interleukin; LGALS1: Galectin-1; LT- $\beta R$ : Lymphotoxin- $\beta$ receptor; mAb: Monoclonal antibody; MDSC: Myeloid-derived suppressor cell; MMP: Matrix metallopeptidase; MVD: Microvascular density; NK: Natural killer; OS: Overall survival; pCR: Pathological complete response; PDGF: Plateletderived growth factor; PDPN: Podoplanin; PFS: Progression-free survival; PLGF: Placental growth factor; ROS: Reactive oxygen species; SDF1: Stromal cell-derived factor-1; STING: Stimulator of interferon gene; SWE: Shear-wave elastography; TAM: Tumor-associated macrophage; TEM: TIE2-expressing macrophage; TGF- $\beta$ : Transforming growth factor- $\beta$; THBS1: Thrombospondin1; TIIC: Tumor-infiltrating immune cell; TKI: Tyrosine kinase inhibitor; TMB: Tumor mutational burden; TME: Tumor microenvironment; TNBC: Triple-negative breast cancer; TOX: Thymocyte selection-associated HMG-box; Tregs: T regulatory cells; VCAM1: Vascular cell adhesion molecule1; VEGF: Vascular endothelial growth factor; VEGFR: Vascular endothelial growth factor receptor
\end{abstract}

\section{Acknowledgments}

The authors thank Dr. Ke Wang, Chao Li, Shanshan Sun, Zhigang Zhang and Prof. Fuming Qiu and Jian Huang for their helpful advice and collaborating for their research work.

\section{Authors' contributions}

Wuzhen Chen and Zhigang Chen designed the stream of thoughts in this review. Lesang Shen and Jingxin Jiang coordinated data acquisition, generated the illustration, and wrote the first draft of the manuscript. Leyi Zhang, Zhigang Zhang and Jun Pan participated in critically revising the manuscript. Chao Ni and Zhigang Chen helped design the study and draft and revise the manuscript. All authors read and approved the final manuscript.

\section{Funding}

This work was supported by the National Natural Science Foundation of China (No: 81972598, CZG), the Zhejiang Medical and Health Science and Technology Plan Project (No: 2019RC040, CWZ), the Natural Science Foundation of Zhejiang Province (No: LQ20H160064, CWZ) and the Fundamental Research Funds for the Central Universities (No: 2021FZ203-0208, CWZ).

Availability of data and materials

Not applicable.

\section{Declarations}

Ethics approval and consent to participate

Not applicable.

Consent for publication

Not applicable.

\section{Competing interests}

The authors declare no o competing interests.

\section{Author details}

${ }^{1}$ Department of Breast Surgery (Surgical Oncology), Second Affiliated Hospital, Zhejiang University School of Medicine, 88 Jiefang Road, Hangzhou 310000, Zhejiang Province, China. ${ }^{2}$ Key Laboratory of Tumor

Microenvironment and Immune Therapy of Zhejiang Province, Hangzhou, China.

Received: 5 January 2021 Accepted: 8 July 2021

Published online: 22 July 2021

\section{References}

1. Jain RK. Normalizing tumor microenvironment to treat cancer: bench to bedside to biomarkers. J Clin Oncol. 2013;31:2205-18. https://doi.org/10.12 00/JCO.2012.46.3653.

2. Jain RK. Antiangiogenesis strategies revisited: from starving tumors to alleviating hypoxia. Cancer Cell. 2014;26:605-22. https://doi.org/10.1016/j. ccell.2014.10.006.

3. Schmid P, Adams S, Rugo HS, Schneeweiss A, Barrios CH, Iwata H, et al. Atezolizumab and nab-paclitaxel in advanced triple-negative breast Cancer. N Engl J Med. 2018;379:2108-21. https://doi.org/10.1056/NEJMoa1809615.

4. Carmeliet $P$, Jain RK. Angiogenesis in cancer and other diseases. Nature. 2000;407:249-57. https://doi.org/10.1038/35025220.

5. Jayson GC, Kerbel R, Ellis LM, Harris AL. Antiangiogenic therapy in oncology: current status and future directions. Lancet. 2016;388:518-29. https://doi. org/10.1016/S0140-6736(15)01088-0.

6. Zheng $X$, Fang Z, Liu X, Deng S, Zhou P, Wang $X$, et al. Increased vessel perfusion predicts the efficacy of immune checkpoint blockade. J Clin Invest. 2018;128:2104-15. https://doi.org/10.1172/JCl96582.

7. Fukumura D, Kloepper J, Amoozgar Z, Duda DG, Jain RK. Enhancing cancer immunotherapy using antiangiogenics: opportunities and challenges. Nat Rev Clin Oncol. 2018;15:325-40. https://doi.org/10.1038/nrclinonc.2018.29.

8. Motz GT, Coukos G. The parallel lives of angiogenesis and immunosuppression: cancer and other tales. Nat Rev Immunol. 2011;11:70211. https://doi.org/10.1038/nri3064.

9. Schmittnaegel M, Rigamonti N, Kadioglu E, Cassara A, Wyser Rmili C, Kiialainen A, et al. Dual angiopoietin-2 and VEGFA inhibition elicits antitumor immunity that is enhanced by PD-1 checkpoint blockade. Sci Transl Med. 2017;9:eaak9670. https://doi.org/10.1126/scitransImed.aak9670.

10. Motz GT, Santoro SP, Wang LP, Garrabrant T, Lastra RR, Hagemann IS, et al. Tumor endothelium FasL establishes a selective immune barrier promoting tolerance in tumors. Nat Med. 2014;20:607-15. https://doi.org/10.1038/nm.3 541.

11. Huang Y, Goel S, Duda DG, Fukumura D, Jain RK. Vascular normalization as an emerging strategy to enhance cancer immunotherapy. Cancer Res. 2013; 73:2943-8. https://doi.org/10.1158/0008-5472.CAN-12-4354.

12. Dikov MM, Ohm JE, Ray N, Tchekneva EE, Burlison J, Moghanaki D, et al. Differential roles of vascular endothelial growth factor receptors 1 and 2 in dendritic cell differentiation. J Immunol. 2005;174:215-22. https://doi.org/1 0.4049/jimmunol.174.1.215. 
13. Gabrilovich D, Ishida T, Oyama T, Ran S, Kravtsov V, Nadaf S, et al. Vascular endothelial growth factor inhibits the development of dendritic cells and dramatically affects the differentiation of multiple hematopoietic lineages in vivo. Blood. 1998;92:4150-66 https://www.ncbi.nlm.nih.gov/pubmed/ 9834220.

14. Lee WS, Yang $H_{1}$ Chon HJ, Kim C. Combination of anti-angiogenic therapy and immune checkpoint blockade normalizes vascular-immune crosstalk to potentiate cancer immunity. Exp Mol Med. 2020;52:1475-85. https://doi. org/10.1038/s12276-020-00500-y.

15. Voron T, Colussi $O$, Marcheteau E, Pernot $S$, Nizard M, Pointet $A L$, et al. VEGF-A modulates expression of inhibitory checkpoints on CD8+ T cells in tumors. J Exp Med. 2015;212:139-48. https://doi.org/10.1084/jem.20140559.

16. Terme M, Pernot S, Marcheteau E, Sandoval F, Benhamouda N, Colussi O, et al. VEGFA-VEGFR pathway blockade inhibits tumor-induced regulatory Tcell proliferation in colorectal cancer. Cancer Res. 2013;73:539-49. https:// doi.org/10.1158/0008-5472.CAN-12-2325.

17. Vetsika EK, Koukos A, Kotsakis A. Myeloid-derived suppressor cells: major figures that shape the immunosuppressive and Angiogenic network in Cancer. Cells. 2019;8:1647. https://doi.org/10.3390/cells8121647.

18. Palazon A, Tyrakis PA, Macias D, Velica P, Rundqvist H, Fitzpatrick S, et al. An HIF-1alpha/NEGF-A Axis in cytotoxic T cells regulates tumor progression. Cancer Cell. 2017;32:669-83 e5. https://doi.org/10.1016/j.ccell.2017.10.003.

19. Kim CG, Jang M, Kim Y, Leem G, Kim KH, Lee H, et al. VEGF-A drives TOXdependent T cell exhaustion in anti-PD-1-resistant microsatellite stable colorectal cancers. Sci Immunol. 2019;4:eaay0555. https://doi.org/10.1126/ sciimmunol.aay0555.

20. Khan O, Giles JR, McDonald S, Manne S, Ngiow SF, Patel KP, et al. TOX transcriptionally and epigenetically programs CD8(+) T cell exhaustion. Nature. 2019;571:211-8. https://doi.org/10.1038/s41586-019-1325-x.

21. Coffelt SB, Chen YY, Muthana M, Welford AF, Tal AO, Scholz A, et al. Angiopoietin 2 stimulates TIE2-expressing monocytes to suppress $T$ cell activation and to promote regulatory T cell expansion. J Immunol. 2011;186: 4183-90. https://doi.org/10.4049/jimmunol.1002802.

22. Murdoch C, Tazzyman S, Webster S, Lewis CE. Expression of tie-2 by human monocytes and their responses to angiopoietin-2. J Immunol. 2007;178: 7405-11. https://doi.org/10.4049/jimmunol.178.11.7405.

23. Khan KA, Kerbel RS. Improving immunotherapy outcomes with antiangiogenic treatments and vice versa. Nat Rev Clin Oncol. 2018;15:310-24. https://doi.org/10.1038/nrclinonc.2018.9.

24. De Falco $\mathrm{S}$. The discovery of placenta growth factor and its biological activity. Exp Mol Med. 2012;44:1-9. https://doi.org/10.3858/emm.2012.44.1.025.

25. Odorisio T, Schietroma C, Zaccaria ML, Cianfarani F, Tiveron C, Tatangelo L, et al. Mice overexpressing placenta growth factor exhibit increased vascularization and vessel permeability. J Cell Sci. 2002;115:2559-67 https:// www.ncbi.nlm.nih.gov/pubmed/12045226.

26. Goumans MJ, Liu Z, ten Dijke P. TGF-beta signaling in vascular biology and dysfunction. Cell Res. 2009;19:116-27. https://doi.org/10.1038/cr.2008.326.

27. Tian M, Neil JR, Schiemann WP. Transforming growth factor-beta and the hallmarks of cancer. Cell Signal. 2011;23:951-62. https://doi.org/10.1016/j. cellsig.2010.10.015

28. Rivera LB, Meyronet D, Hervieu V, Frederick MJ, Bergsland E, Bergers G. Intratumoral myeloid cells regulate responsiveness and resistance to antiangiogenic therapy. Cell Rep. 2015;11:577-91. https://doi.org/10.1016/j. celrep.2015.03.055

29. Shojaei F, Wu X, Malik AK, Zhong C, Baldwin ME, Schanz S, et al. Tumor refractoriness to anti-VEGF treatment is mediated by $C D 11 b+G r 1+$ myeloid cells. Nat Biotechnol. 2007;25:911-20. https://doi.org/10.1038/nbt1323.

30. Huang Y, Kim BYS, Chan CK, Hahn SM, Weissman IL, Jiang W. Improving immune-vascular crosstalk for cancer immunotherapy. Nat Rev Immunol. 2018;18:195-203. https://doi.org/10.1038/nri.2017.145.

31. Rahma OE, Hodi FS. The intersection between tumor angiogenesis and immune suppression. Clin Cancer Res. 2019:25:5449-57. https://doi.org/10.11 58/1078-0432.CCR-18-1543

32. Bruno A, Pagani A, Pulze L, Albini A, Dallaglio K, Noonan DM, et al. Orchestration of angiogenesis by immune cells. Front Oncol. 2014;4:131. https://doi.org/10.3389/fonc.2014.00131.

33. Stockmann C, Schadendorf D, Klose R, Helfrich I. The impact of the immune system on tumor: angiogenesis and vascular remodeling. Front Oncol. 2014; 4:69. https://doi.org/10.3389/fonc.2014.00069.

34. Ahmed FS, Gaule P, McGuire J, Patel K, Blenman K, Pusztai L, et al. PD-L1 protein expression on both tumor cells and macrophages are associated with response to Neoadjuvant Durvalumab with chemotherapy in triplenegative breast Cancer. Clin Cancer Res. 2020;26:5456-61. https://doi.org/1 0.1158/1078-0432.CCR-20-1303.

35. Biswas SK, Mantovani A. Macrophage plasticity and interaction with lymphocyte subsets: cancer as a paradigm. Nat Immunol. 2010;11:889-96. https://doi.org/10.1038/ni.1937.

36. Albini A, Bruno A, Noonan DM, Mortara L. Contribution to tumor angiogenesis from innate immune cells within the tumor microenvironment: implications for immunotherapy. Front Immunol. 2018;9: 527. https://doi.org/10.3389/fimmu.2018.00527.

37. Rivera LB, Bergers $G$. Intertwined regulation of angiogenesis and immunity by myeloid cells. Trends Immunol. 2015;36:240-9. https://doi.org/10.1016/j. it.2015.02.005

38. Qian BZ, Pollard JW. Macrophage diversity enhances tumor progression and metastasis. Cell. 2010;141:39-51. https://doi.org/10.1016/j.cell.2010.03.014.

39. Chen $\mathrm{P}$, Bonaldo $\mathrm{P}$. Role of macrophage polarization in tumor angiogenesis and vessel normalization: implications for new anticancer therapies. Int Rev Cell Mol Biol. 2013;301:1-35. https://doi.org/10.1016/B978-0-12-407704-1. 00001-4.

40. Watkins SK, Egilmez NK, Suttles J, Stout RD. IL-12 rapidly alters the functional profile of tumor-associated and tumor-infiltrating macrophages in vitro and in vivo. J Immunol. 2007;178:1357-62. https://doi.org/10.4049/ jimmunol.178.3.1357.

41. Mantovani A, Biswas SK, Galdiero MR, Sica A, Locati M. Macrophage plasticity and polarization in tissue repair and remodelling. J Pathol. 2013; 229:176-85. https://doi.org/10.1002/path.4133.

42. Kloepper J, Riedemann L, Amoozgar Z, Seano G, Susek K, Yu V, et al. Ang-2/ VEGF bispecific antibody reprograms macrophages and resident microglia to anti-tumor phenotype and prolongs glioblastoma survival. Proc Natl Acad Sci U S A. 2016;113:4476-81. https://doi.org/10.1073/pnas.1525360113.

43. Peterson TE, Kirkpatrick ND, Huang Y, Farrar CT, Marijt KA, Kloepper J, et al. Dual inhibition of Ang-2 and VEGF receptors normalizes tumor vasculature and prolongs survival in glioblastoma by altering macrophages. Proc Natl Acad Sci U S A. 2016;113:4470-5. https://doi.org/10.1073/pnas.1525349113.

44. Reusser NM, Dalton HJ, Pradeep S, Gonzalez-Villasana V, Jennings NB, Vasquez HG, et al. Clodronate inhibits tumor angiogenesis in mouse models of ovarian cancer. Cancer Biol Ther. 2014;15:1061-7. https://doi.org/10.4161/ cbt.29184.

45. Zeisberger SM, Odermatt B, Marty C, Zehnder-Fjallman AH, Ballmer-Hofer K, Schwendener RA. Clodronate-liposome-mediated depletion of tumourassociated macrophages: a new and highly effective antiangiogenic therapy approach. Br J Cancer. 2006;95:272-81. https://doi.org/10.1038/sj.bjc.660324

46. Mazzieri R, Pucci F, Moi D, Zonari E, Ranghetti A, Berti A, et al. Targeting the ANG2/TIE2 axis inhibits tumor growth and metastasis by impairing angiogenesis and disabling rebounds of proangiogenic myeloid cells. Cancer Cell. 2011;19:512-26. https://doi.org/10.1016/j.ccr.2011.02.005.

47. De Palma M, Murdoch C, Venneri MA, Naldini L, Lewis CE. Tie2-expressing monocytes: regulation of tumor angiogenesis and therapeutic implications. Trends Immunol. 2007;28:519-24. https://doi.org/10.1016/j.it.2007.09.004.

48. Piqueras B, Connolly J, Freitas H, Palucka AK, Banchereau J. Upon viral exposure, myeloid and plasmacytoid dendritic cells produce 3 waves of distinct chemokines to recruit immune effectors. Blood. 2006;107:2613-8. https://doi.org/10.1182/blood-2005-07-2965.

49. Trinchieri G. Interleukin-12 and the regulation of innate resistance and adaptive immunity. Nat Rev Immunol. 2003;3:133-46. https://doi.org/10.103 8/nri1001.

50. Asselin-Paturel C, Trinchieri G. Production of type I interferons: plasmacytoid dendritic cells and beyond. J Exp Med. 2005;202:461-5. https://doi.org/10.1 084/jem.20051395.

51. Kammertoens T, Friese C, Arina A, Idel C, Briesemeister D, Rothe M, et al Tumour ischaemia by interferon-gamma resembles physiological blood vessel regression. Nature. 2017;545:98-102. https://doi.org/10.1038/na ture22311.

52. Yang H, Lee WS, Kong SJ, Kim CG, Kim JH, Chang SK, et al. STING activation reprograms tumor vasculatures and synergizes with VEGFR2 blockade. J Clin Invest. 2019;129:4350-64. https://doi.org/10.1172/JCl125413.

53. Fathallah-Shaykh HM, Zhao LJ, Kafrouni Al, Smith GM, Forman J. Gene transfer of IFN-gamma into established brain tumors represses growth by antiangiogenesis. J Immunol. 2000;164:217-22. https://doi.org/10.4049/ jimmunol.164.1.217. 
54. Baer C, Squadrito ML, Laoui D, Thompson D, Hansen SK, Kiialainen A, et al. Suppression of microRNA activity amplifies IFN-gamma-induced macrophage activation and promotes anti-tumour immunity. Nat Cell Biol. 2016;18:790-802. https://doi.org/10.1038/ncb3371.

55. Bromley SK, Mempel TR, Luster AD. Orchestrating the orchestrators: chemokines in control of T cell traffic. Nat Immunol. 2008;9:970-80. https:// doi.org/10.1038/ni.f.213.

56. Freedman RS, Kudelka AP, Kavanagh JJ, Verschraegen C, Edwards CL, Nash $M$, et al. Clinical and biological effects of intraperitoneal injections of recombinant interferon-gamma and recombinant interleukin 2 with or without tumor-infiltrating lymphocytes in patients with ovarian or peritoneal carcinoma. Clin Cancer Res. 2000;6:2268-78 https://www.ncbi. nlm.nih.gov/pubmed/10873077.

57. Tian L, Goldstein A, Wang H, Ching Lo H, Sun Kim I, Welte T, et al. Mutual regulation of tumour vessel normalization and immunostimulatory reprogramming. Nature. 2017;544:250-4. https://doi.org/10.1038/nature21 724.

58. Balkwill FR, Capasso M, Hagemann T. The tumor microenvironment at a glance. J Cell Sci. 2012;125:5591-6. https://doi.org/10.1242/jcs.116392.

59. Heusinkveld M, de Vos van Steenwijk PJ, Goedemans R, Ramwadhdoebe TH, Gorter A, Welters MJ, et al. M2 macrophages induced by prostaglandin E2 and IL-6 from cervical carcinoma are switched to activated M1 macrophages by CD4+ Th1 cells. J Immunol. 2011;187:1157-65. https://doi. org/10.4049/jimmunol.1100889.

60. DeNardo DG, Barreto JB, Andreu P, Vasquez L, Tawfik D, Kolhatkar N, et al. $\mathrm{CD} 4(+) \mathrm{T}$ cells regulate pulmonary metastasis of mammary carcinomas by enhancing protumor properties of macrophages. Cancer Cell. 2009;16:91102. https://doi.org/10.1016/j.ccr.2009.06.018.

61. Liu J, Duan Y, Cheng X, Chen X, Xie W, Long H, et al. IL-17 is associated with poor prognosis and promotes angiogenesis via stimulating VEGF production of cancer cells in colorectal carcinoma. Biochem Biophys Res Commun. 2011;407:348-54. https://doi.org/10.1016/.jbbrc.2011.03.021.

62. Iida T, Iwahashi M, Katsuda M, Ishida K, Nakamori M, Nakamura M, et al. Tumor-infiltrating CD4+ Th17 cells produce IL-17 in tumor microenvironment and promote tumor progression in human gastric cancer. Oncol Rep. 2011;25:1271-7. https://doi.org/10.3892/or.2011.1201.

63. Ren L, Yu Y, Wang L, Zhu Z, Lu R, Yao Z. Hypoxia-induced CCL28 promotes recruitment of regulatory $T$ cells and tumor growth in liver cancer. Oncotarget. 2016;7:75763-73. https://doi.org/10.18632/oncotarget.12409.

64. Yang J, Yan J, Liu B. Targeting VEGFNEGFR to modulate antitumor immunity. Front Immunol. 2018;9:978. https://doi.org/10.3389/fimmu.2018.00978.

65. Facciabene A, Motz GT, Coukos G. T-regulatory cells: key players in tumor immune escape and angiogenesis. Cancer Res. 2012;72:2162-71. https://doi. org/10.1158/0008-5472.CAN-11-3687.

66. Facciabene A, Peng X, Hagemann IS, Balint K, Barchetti A, Wang LP, et al. Tumour hypoxia promotes tolerance and angiogenesis via CCL28 and T(reg) cells. Nature. 2011:475:226-30. https://doi.org/10.1038/nature10169.

67. Bruno A, Mortara L, Baci D, Noonan DM, Albini A. Myeloid derived suppressor cells interactions with natural killer cells and pro-angiogenic activities: roles in tumor progression. Front Immunol. 2019;10:771. https:// doi.org/10.3389/fimmu.2019.00771.

68. Kumar V, Patel S, Tcyganov E, Gabrilovich DI. The nature of myeloid-derived suppressor cells in the tumor microenvironment. Trends Immunol. 2016;37: 208-20. https://doi.org/10.1016/j.it.2016.01.004.

69. Yang L, DeBusk LM, Fukuda K, Fingleton B, Green-Jarvis B, Shyr Y, et al. Expansion of myeloid immune suppressor gr+CD11b+ cells in tumorbearing host directly promotes tumor angiogenesis. Cancer Cell. 2004;6: 409-21. https://doi.org/10.1016/j.ccr.2004.08.031.

70. Kujawski M, Kortylewski M, Lee H, Herrmann A, Kay H, Yu H. Stat3 mediates myeloid cell-dependent tumor angiogenesis in mice. J Clin Invest. 2008;118: 3367-77. https://doi.org/10.1172/JCl35213.

71. Murdoch C, Muthana M, Coffelt SB, Lewis CE. The role of myeloid cells in the promotion of tumour angiogenesis. Nat Rev Cancer. 2008;8:618-31. https://doi.org/10.1038/nrc2444

72. Fleming V, Hu X, Weber R, Nagibin V, Groth C, Altevogt P, et al. Targeting myeloid-derived suppressor cells to bypass tumor-induced immunosuppression. Front Immunol. 2018;9:398. https://doi.org/10.3389/fimmu.2018.00398.

73. Guedez L, Jensen-Taubman S, Bourboulia D, Kwityn CJ, Wei B, Caterina J, et al. TIMP-2 targets tumor-associated myeloid suppressor cells with effects in cancer immune dysfunction and angiogenesis. J Immunother. 2012;35: 502-12. https://doi.org/10.1097/CJl.0b013e3182619c8e.
74. Karakhanova S, Link J, Heinrich M, Shevchenko I, Yang Y, Hassenpflug M, et al. Characterization of myeloid leukocytes and soluble mediators in pancreatic cancer: importance of myeloid-derived suppressor cells. Oncoimmunology. 2015;4:e998519. https://doi.org/10.1080/2162402X.2014. 998519.

75. Jayaraman P, Parikh F, Lopez-Rivera E, Hailemichael Y, Clark A, Ma G, et al. Tumor-expressed inducible nitric oxide synthase controls induction of functional myeloid-derived suppressor cells through modulation of vascular endothelial growth factor release. J Immunol. 2012;188:5365-76. https://doi. org/10.4049/jimmunol.1103553.

76. Horikawa N, Abiko K, Matsumura N, Hamanishi J, Baba T, Yamaguchi K, et al. Expression of vascular endothelial growth factor in ovarian Cancer inhibits tumor immunity through the accumulation of myeloid-derived suppressor cells. Clin Cancer Res. 2017;23:587-99. https://doi.org/10.1158/1078-0432. CCR-16-0387.

77. Ferrara N. Role of myeloid cells in vascular endothelial growth factorindependent tumor angiogenesis. Curr Opin Hematol. 2010;17:219-24. https://doi.org/10.1097/MOH.0b013e3283386660.

78. Madar S, Goldstein I, Rotter V. 'Cancer associated fibroblasts'--more than meets the eye. Trends Mol Med. 2013;19:447-53. https://doi.org/10.1016/j. molmed.2013.05.004

79. Gonda TA, Varro A, Wang TC, Tycko B. Molecular biology of cancerassociated fibroblasts: can these cells be targeted in anti-cancer therapy? Semin Cell Dev Biol. 2010;21:2-10. https://doi.org/10.1016/j.semcdb.2009.10. 001.

80. Wang FT, Sun W, Zhang JT, Fan YZ. Cancer-associated fibroblast regulation of tumor neo-angiogenesis as a therapeutic target in cancer. Oncol Lett. 2019:17:3055-65. https://doi.org/10.3892/ol.2019.9973.

81. Orimo A, Gupta PB, Sgroi DC, Arenzana-Seisdedos F, Delaunay T, Naeem R, et al. Stromal fibroblasts present in invasive human breast carcinomas promote tumor growth and angiogenesis through elevated SDF-1/CXCL12 secretion. Cell. 2005;121:335-48. https://doi.org/10.1016/j.cell.2005.02.034

82. Fukumura D, Xavier R, Sugiura T, Chen Y, Park EC, Lu N, et al. Tumor induction of VEGF promoter activity in stromal cells. Cell. 1998;94:715-25. https://doi.org/10.1016/s0092-8674(00)81731-6.

83. Schoppmann SF, Jesch B, Riegler MF, Maroske F, Schwameis K, Jomrich G, et al. Podoplanin expressing cancer associated fibroblasts are associated with unfavourable prognosis in adenocarcinoma of the esophagus. Clin Exp Metastasis. 2013;30:441-6. https://doi.org/10.1007/s10585-012-9549-2.

84. Pula B, Jethon A, Piotrowska A, Gomulkiewicz A, Owczarek T, Calik J, et al. Podoplanin expression by cancer-associated fibroblasts predicts poor outcome in invasive ductal breast carcinoma. Histopathology. 2011;59:124960. https://doi.org/10.1111/j.1365-2559.2011.04060.x.

85. Pula B, Wojnar A, Witkiewicz W, Dziegiel P, Podhorska-Okolow M. Podoplanin expression in cancer-associated fibroblasts correlates with VEGFC expression in cancer cells of invasive ductal breast carcinoma. Neoplasma. 2013;60:516-24. https://doi.org/10.4149/neo_2013_067.

86. Tang D, Yuan Z, Xue X, Lu Z, Zhang Y, Wang H, et al. High expression of Galectin-1 in pancreatic stellate cells plays a role in the development and maintenance of an immunosuppressive microenvironment in pancreatic cancer. Int J Cancer. 2012;130:2337-48. https://doi.org/10.1002/ijc.26290.

87. Wu MH, Hong TM, Cheng HW, Pan SH, Liang YR, Hong HC, et al. Galectin-1mediated tumor invasion and metastasis, up-regulated matrix metalloproteinase expression, and reorganized actin cytoskeletons. Mol Cancer Res. 2009;7:311-8. https://doi.org/10.1158/1541-7786.MCR-08-0297.

88. Thijssen VL, Postel R, Brandwijk RJ, Dings RP, Nesmelova I, Satijn S, et al. Galectin-1 is essential in tumor angiogenesis and is a target for antiangiogenesis therapy. Proc Natl Acad Sci U S A. 2006;103:15975-80. https://doi.org/10.1073/pnas.0603883103.

89. Tang D, Gao J, Wang S, Ye N, Chong Y, Huang Y, et al. Cancer-associated fibroblasts promote angiogenesis in gastric cancer through galectin-1 expression. Tumour Biol. 2016;37:1889-99. https://doi.org/10.1007/s13277-015-3942-9.

90. Ren J, Guo H, Wu H, Tian T, Dong D, Zhang Y, et al. GPER in CAFs regulates hypoxia-driven breast cancer invasion in a CTGF-dependent manner. Oncol Rep. 2015;33:1929-37. https://doi.org/10.3892/or.2015.3779.

91. De Francesco EM, Lappano R, Santolla MF, Marsico S, Caruso A, Maggiolini M. HIF-1alpha/GPER signaling mediates the expression of VEGF induced by hypoxia in breast cancer associated fibroblasts (CAFs). Breast Cancer Res. 2013;15:R64. https://doi.org/10.1186/bcr3458.

92. Lederle W, Hartenstein B, Meides A, Kunzelmann H, Werb Z, Angel P, et al. MMP13 as a stromal mediator in controlling persistent angiogenesis in skin 
carcinoma. Carcinogenesis. 2010;31:1175-84. https://doi.org/10.1093/carcin/ bgp248.

93. Crawford Y, Kasman I, Yu L, Zhong C, Wu X, Modrusan Z, et al. PDGF-C mediates the angiogenic and tumorigenic properties of fibroblasts associated with tumors refractory to anti-VEGF treatment. Cancer Cell. 2009; 15:21-34. https://doi.org/10.1016/i.ccr.2008.12.004.

94. Tong RT, Boucher Y, Kozin SV, Winkler F, Hicklin DJ, Jain RK. Vascular normalization by vascular endothelial growth factor receptor 2 blockade induces a pressure gradient across the vasculature and improves drug penetration in tumors. Cancer Res. 2004;64:3731-6. https://doi.org/10.1158/ 0008-5472.CAN-04-0074.

95. Huang Y, Yuan J, Righi E, Kamoun WS, Ancukiewicz M, Nezivar J, et al. Vascular normalizing doses of antiangiogenic treatment reprogram the immunosuppressive tumor microenvironment and enhance immunotherapy. Proc Natl Acad Sci U S A. 2012;109:17561-6. https://doi. org/10.1073/pnas.1215397109.

96. Shrimali RK, Yu Z, Theoret MR, Chinnasamy D, Restifo NP, Rosenberg SA. Antiangiogenic agents can increase lymphocyte infiltration into tumor and enhance the effectiveness of adoptive immunotherapy of cancer. Cancer Res. 2010;70:6171-80. https://doi.org/10.1158/0008-5472.CAN-10-0153.

97. Shigeta K, Matsui A, Kikuchi H, Klein S, Mamessier E, Chen IX, et al. Regorafenib combined with PD1 blockade increases CD8 T-cell infiltration by inducing CXCL10 expression in hepatocellular carcinoma. J Immunother Cancer. 2020;8:e001435. https://doi.org/10.1136/jitc-2020-001435.

98. Castro BA, Flanigan P, Jahangiri A, Hoffman D, Chen W, Kuang R, et al. Macrophage migration inhibitory factor downregulation: a novel mechanism of resistance to anti-angiogenic therapy. Oncogene. 2017;36: 3749-59. https://doi.org/10.1038/onc.2017.1.

99. Zhou X, Hou W, Gao L, Shui L, Yi C, Zhu H. Synergies of Antiangiogenic therapy and immune checkpoint blockade in renal cell carcinoma: from theoretical background to clinical reality. Front Oncol. 2020;10:1321. https:// doi.org/10.3389/fonc.2020.01321.

100. Hendry SA, Farnsworth RH, Solomon B, Achen MG, Stacker SA, Fox SB. The role of the tumor vasculature in the host immune response: implications for therapeutic strategies targeting the tumor microenvironment. Front Immunol. 2016;7:621. https://doi.org/10.3389/fimmu.2016.00621.

101. Allen E, Jabouille A, Rivera LB, Lodewijckx I, Missiaen R, Steri V, et al. Combined antiangiogenic and anti-PD-L1 therapy stimulates tumor immunity through HEV formation. Sci Transl Med. 2017;9:eaak9679. https:// doi.org/10.1126/scitranslmed.aak9679.

102. Farnsworth RH, Karnezis T, Shayan R, Matsumoto M, Nowell CJ, Achen MG, et al. A role for bone morphogenetic protein-4 in lymph node vascular remodeling and primary tumor growth. Cancer Res. 2011;71:6547-57. https://doi.org/10.1158/0008-5472.CAN-11-0200.

103. Qian CN, Berghuis B, Tsarfaty G, Bruch M, Kort EJ, Ditlev J, et al. Preparing the "soil": the primary tumor induces vasculature reorganization in the sentinel lymph node before the arrival of metastatic cancer cells. Cancer Res. 2006;66:10365-76. https://doi.org/10.1158/0008-5472.CAN-06-2977.

104. Carriere V, Colisson R, Jiguet-Jiglaire C, Bellard E, Bouche G, Al Saati T, et al. Cancer cells regulate lymphocyte recruitment and leukocyte-endothelium interactions in the tumor-draining lymph node. Cancer Res. 2005;65:1163948. https://doi.org/10.1158/0008-5472.CAN-05-1190.

105. Rahbari NN, Kedrin D, Incio J, Liu H, Ho WW, Nia HT, et al. Anti-VEGF therapy induces ECM remodeling and mechanical barriers to therapy in colorectal cancer liver metastases. Sci Transl Med. 2016;8:360ra135. https:// doi.org/10.1126/scitranslmed.aaf5219.

106. Chen Y, Ramjiawan RR, Reiberger T, Ng MR, Hato T, Huang Y, et al. CXCR4 inhibition in tumor microenvironment facilitates anti-programmed death receptor-1 immunotherapy in sorafenib-treated hepatocellular carcinoma in mice. Hepatology. 2015;61:1591-602. https://doi.org/10.1002/hep.27665.

107. Griveau A, Seano G, Shelton SJ, Kupp R, Jahangiri A, Obernier K, et al. A glial signature and Wnt7 signaling regulate Glioma-vascular interactions and tumor microenvironment. Cancer Cell. 2018;33:874-89 e7. https://doi.org/1 0.1016/j.ccell.2018.03.020

108. Conley SJ, Gheordunescu E, Kakarala P, Newman B, Korkaya H, Heath AN, et al. Antiangiogenic agents increase breast cancer stem cells via the generation of tumor hypoxia. Proc Natl Acad Sci U S A. 2012;109:2784-9. https://doi.org/10.1073/pnas.1018866109.

109. Yang MH, Wu MZ, Chiou SH, Chen PM, Chang SY, Liu CJ, et al. Direct regulation of TWIST by HIF-1alpha promotes metastasis. Nat Cell Biol. 2008; 10:295-305. https://doi.org/10.1038/ncb1691.
110. Tolaney SM, Boucher Y, Duda DG, Martin JD, Seano G, Ancukiewicz M, et al. Role of vascular density and normalization in response to neoadjuvant bevacizumab and chemotherapy in breast cancer patients. Proc Natl Acad Sci U S A. 2015;112:14325-30. https://doi.org/10.1073/pnas.1518808112.

111. Hegde PS, Jubb AM, Chen D, Li NF, Meng YG, Bernaards C, et al. Predictive impact of circulating vascular endothelial growth factor in four phase III trials evaluating bevacizumab. Clin Cancer Res. 2013;19:929-37. https://doi. org/10.1158/1078-0432.CCR-12-2535.

112. Winkler F, Kozin SV, Tong RT, Chae SS, Booth MF, Garkavtsev I, et al. Kinetics of vascular normalization by VEGFR2 blockade governs brain tumor response to radiation: role of oxygenation, angiopoietin-1, and matrix metalloproteinases. Cancer Cell. 2004;6:553-63. https://doi.org/10.1016/j.ccr.2 004.10.011.

113. Batchelor TT, Duda DG, di Tomaso E, Ancukiewicz M, Plotkin SR, Gerstner E, et al. Phase II study of cediranib, an oral pan-vascular endothelial growth factor receptor tyrosine kinase inhibitor, in patients with recurrent glioblastoma. J Clin Oncol. 2010;28:2817-23. https://doi.org/10.1200/JCO.2 009.26.3988.

114. Wu X, Giobbie-Hurder A, Liao X, Connelly C, Connolly EM, Li J, et al. Angiopoietin-2 as a biomarker and target for immune checkpoint therapy. Cancer Immunol Res. 2017;5:17-28. https://doi.org/10.1158/2326-6066.CIR-1 6-0206.

115. Chae SS, Kamoun WS, Farrar CT, Kirkpatrick ND, Niemeyer E, de Graaf AM, et al. Angiopoietin-2 interferes with anti-VEGFR2-induced vessel normalization and survival benefit in mice bearing gliomas. Clin Cancer Res. 2010;16:3618-27. https://doi.org/10.1158/1078-0432.CCR-09-3073.

116. Kienast Y, Klein C, Scheuer W, Raemsch R, Lorenzon E, Bernicke D, et al. Ang-2-VEGF-A CrossMab, a novel bispecific human IgG1 antibody blocking VEGF-A and Ang-2 functions simultaneously, mediates potent antitumor, antiangiogenic, and antimetastatic efficacy. Clin Cancer Res. 2013;19:673040. https://doi.org/10.1158/1078-0432.CCR-13-0081.

117. Wu FT, Man S, Xu P, Chow A, Paez-Ribes M, Lee CR, et al. Efficacy of Cotargeting Angiopoietin-2 and the VEGF pathway in the adjuvant postsurgical setting for early breast, colorectal, and renal cancers. Cancer Res. 2016;76:6988-7000. https://doi.org/10.1158/0008-5472.CAN-16-0888.

118. Bendell JC, Sauri T, Gracian AC, Alvarez R, Lopez-Lopez C, Garcia-Alfonso P, et al. The McCAVE trial: Vanucizumab plus mFOLFOX-6 versus Bevacizumab plus mFOLFOX-6 in patients with previously untreated metastatic colorectal carcinoma (mCRC). Oncologist. 2020;25:e451-e9. https://doi.org/10.1634/ theoncologist.2019-0291.

119. Mpekris F, Voutouri C, Baish JW, Duda DG, Munn LL, Stylianopoulos T, et al. Combining microenvironment normalization strategies to improve cancer immunotherapy. Proc Natl Acad Sci U S A. 2020;117:3728-37. https://doi. org/10.1073/pnas.1919764117.

120. Sitkovsky MV, Kjaergaard J, Lukashev D, Ohta A. Hypoxia-adenosinergic immunosuppression: tumor protection by T regulatory cells and cancerous tissue hypoxia. Clin Cancer Res. 2008;14:5947-52. https://doi.org/10.1158/1 078-0432.CCR-08-0229.

121. Curiel TJ, Coukos G, Zou L, Alvarez X, Cheng P, Mottram P, et al. Specific recruitment of regulatory $T$ cells in ovarian carcinoma fosters immune privilege and predicts reduced survival. Nat Med. 2004;10:942-9. https//doi.org/10.1038/nm1093.

122. Carretero R, Sektioglu IM, Garbi N, Salgado OC, Beckhove P, Hammerling GJ. Eosinophils orchestrate cancer rejection by normalizing tumor vessels and enhancing infiltration of CD8(+) T cells. Nat Immunol. 2015;16:609-17. https://doi.org/10.1038/ni.3159.

123. De Palma M, Jain RK. CD4(+) T cell activation and vascular normalization: two sides of the same coin? Immunity. 2017;46:773-5. https://doi.org/10.101 6/j.immuni.2017.04.015.

124. Garrido F, Ruiz-Cabello F, Cabrera T, Perez-Villar JJ, Lopez-Botet M, DugganKeen $\mathrm{M}$, et al. Implications for immunosurveillance of altered HLA class I phenotypes in human tumours. Immunol Today. 1997;18:89-95. https://doi. org/10.1016/s0167-5699(96)10075-X.

125. Marincola FM, Jaffee EM, Hicklin DJ, Ferrone S. Escape of human solid tumors from T-cell recognition: molecular mechanisms and functional significance. Adv Immunol. 2000;74:181-273. https://doi.org/10.1016/s0065-2776(08)60911-6.

126. Garrido F, Algarra I. MHC antigens and tumor escape from immune surveillance. Adv Cancer Res. 2001;83:117-58. https://doi.org/10.1016/ s0065-230x(01)83005-0.

127. Seliger B, Cabrera T, Garrido F, Ferrone S. HLA class I antigen abnormalities and immune escape by malignant cells. Semin Cancer Biol. 2002;12:3-13. https://doi.org/10.1006/scbi.2001.0404 
128. Garrido F, Aptsiauri N, Doorduijn EM, Garcia Lora AM, van Hall T. The urgent need to recover MHC class I in cancers for effective immunotherapy. Curr Opin Immunol. 2016;39:44-51. https://doi.org/10.1016/j.coi.2015.12.007.

129. del Campo AB, Kyte JA, Carretero J, Zinchencko S, Mendez R, GonzalezAseguinolaza $\mathrm{G}$, et al. Immune escape of cancer cells with beta2microglobulin loss over the course of metastatic melanoma. Int J Cancer. 2014;134:102-13. https://doi.org/10.1002/ijc.28338.

130. Carretero R, Romero JM, Ruiz-Cabello F, Maleno I, Rodriguez F, Camacho FM, et al. Analysis of HLA class I expression in progressing and regressing metastatic melanoma lesions after immunotherapy. Immunogenetics. 2008; 60:439-47. https://doi.org/10.1007/s00251-008-0303-5.

131. Dhatchinamoorthy K, Colbert JD, Rock KL. Cancer immune evasion through loss of MHC class I antigen presentation. Front Immunol. 2021;12:636568. https://doi.org/10.3389/fimmu.2021.636568.

132. Goodman AM, Castro A, Pyke RM, Okamura R, Kato S, Riviere P, et al. MHC-I genotype and tumor mutational burden predict response to immunotherapy. Genome Med. 2020;12:45. https://doi.org/10.1186/s13073020-00743-4.

133. Wallin JJ, Bendell JC, Funke R, Sznol M, Korski K, Jones S, et al. Atezolizumab in combination with bevacizumab enhances antigen-specific T-cell migration in metastatic renal cell carcinoma. Nat Commun. 2016;7:12624. https://doi.org/10.1038/ncomms12624.

134. Bujor IS, Cioca A, Ceausu RA, Veaceslav F, Nica C, Cimpean AM, et al. Evaluation of Vascular Proliferation in Molecular Subtypes of Breast Cancer In Vivo. 2018;32:79-83. https://doi.org/10.21873/invivo.11207.

135. Nalwoga $H$, Arnes JB, Stefansson IM, Wabinga H, Foulkes WD, Akslen LA. Vascular proliferation is increased in basal-like breast cancer. Breast Cancer Res Treat. 2011;130:1063-71. https://doi.org/10.1007/s10549-011-1740-7.

136. Kruger K, Stefansson IM, Collett K, Arnes JB, Aas T, Akslen LA. Microvessel proliferation by co-expression of endothelial nestin and Ki-67 is associated with a basal-like phenotype and aggressive features in breast cancer. Breast. 2013;22:282-8. https://doi.org/10.1016/j.breast.2012.07.008.

137. Sikov WM, Berry DA, Perou CM, Singh B, Cirrincione CT, Tolaney SM, et al. Impact of the addition of carboplatin and/or bevacizumab to neoadjuvant once-per-week paclitaxel followed by dose-dense doxorubicin and cyclophosphamide on pathologic complete response rates in stage II to III triple-negative breast cancer: CALGB 40603 (Alliance). J Clin Oncol. 2015;33: 13-21. https://doi.org/10.1200/JCO.2014.57.0572.

138. Kim HR, Jung KH, Im SA, Im YH, Kang SY, Park KH, et al. Multicentre phase II trial of bevacizumab combined with docetaxel-carboplatin for the neoadjuvant treatment of triple-negative breast cancer (KCSG BR-0905). Ann Oncol. 2013;24:1485-90. https://doi.org/10.1093/annonc/mds658.

139. Gerber B, Loibl S, Eidtmann H, Rezai M, Fasching PA, Tesch H, et al. Neoadjuvant bevacizumab and anthracycline-taxane-based chemotherapy in 678 triple-negative primary breast cancers; results from the geparquinto study (GBG 44). Ann Oncol. 2013;24:2978-84. https://doi.org/10.1093/a nnonc/mdt361.

140. Thomssen C, Pierga JY, Pritchard KI, Biganzoli L, Cortes-Funes H, Petrakova K, et al. First-line bevacizumab-containing therapy for triple-negative breast cancer: analysis of 585 patients treated in the ATHENA study. Oncology. 2012:82:218-27. https://doi.org/10.1159/000336892.

141. Robert NJ, Dieras V, Glaspy J, Brufsky AM, Bondarenko I, Lipatov ON, et al. RIBBON-1: randomized, double-blind, placebo-controlled, phase III trial of chemotherapy with or without bevacizumab for first-line treatment of human epidermal growth factor receptor 2-negative, locally recurrent or metastatic breast cancer. J Clin Oncol. 2011; 29:1252-60. https://doi.org/10.1200/JCO.2010.28.0982.

142. Hamilton E, Kimmick G, Hopkins J, Marcom PK, Rocha G, Welch R, et al. Nabpaclitaxel/bevacizumab/carboplatin chemotherapy in first-line triple negative metastatic breast cancer. Clin Breast Cancer. 2013;13:416-20. https://doi.org/10.1016/j.clbc.2013.08.003.

143. Brufsky A, Valero V, Tiangco B, Dakhil S, Brize A, Rugo HS, et al. Second-line bevacizumab-containing therapy in patients with triple-negative breast cancer: subgroup analysis of the RIBBON-2 trial. Breast Cancer Res Treat. 2012;133:1067-75. https://doi.org/10.1007/s10549-012-2008-6.

144. Sasich LD, Sukkari SR. The US FDAs withdrawal of the breast cancer indication for Avastin (bevacizumab). Saudi Pharm J. 2012;20:381-5. https:// doi.org/10.1016/j.jsps.2011.12.001.

145. Cameron D, Brown J, Dent R, Jackisch C, Mackey J, Pivot X, et al. Adjuvant bevacizumab-containing therapy in triple-negative breast cancer (BEATRICE): primary results of a randomised, phase 3 trial. Lancet Oncol. 2013;14:933-42. https://doi.org/10.1016/S1470-2045(13)70335-8.
146. Yi M, Jiao D, Qin S, Chu Q, Wu K, Li A. Synergistic effect of immune checkpoint blockade and anti-angiogenesis in cancer treatment. Mol Cancer. 2019;18:60. https://doi.org/10.1186/s12943-019-0974-6.

147. Izumi Y, Xu L, di Tomaso E, Fukumura D, Jain RK. Tumour biology: herceptin acts as an anti-angiogenic cocktail. Nature. 2002;416:279-80. https://doi. org/10.1038/416279b.

148. Mpekris F, Baish JW, Stylianopoulos T, Jain RK. Role of vascular normalization in benefit from metronomic chemotherapy. Proc Natl Acad Sci U S A. 2017; 114:1994-9. https://doi.org/10.1073/pnas.1700340114.

149. Goel S, DeCristo MJ, Watt AC, BrinJones H, Sceneay J, Li BB, et al. CDK4/6 inhibition triggers anti-tumour immunity. Nature. 2017;548:471-5. https:// doi.org/10.1038/nature23465.

150. Cortes J, Cescon DW, Rugo HS, Nowecki Z, Im SA, Yusof MM, et al. Pembrolizumab plus chemotherapy versus placebo plus chemotherapy for previously untreated locally recurrent inoperable or metastatic triplenegative breast cancer (KEYNOTE-355): a randomised, placebo-controlled, double-blind, phase 3 clinical trial. Lancet. 2020;396:1817-28. https://doi. org/10.1016/50140-6736(20)32531-9.

151. Nanda R, Liu MC, Yau C, Shatsky R, Pusztai L, Wallace A, et al. Effect of Pembrolizumab plus Neoadjuvant chemotherapy on pathologic complete response in women with early-stage breast Cancer: an analysis of the ongoing phase 2 adaptively randomized I-SPY2 trial. JAMA Oncol. 2020;6: 676-84. https://doi.org/10.1001/jamaoncol.2019.6650.

152. Karn T, Denkert C, Weber KE, Holtrich U, Hanusch C, Sinn BV, et al. Tumor mutational burden and immune infiltration as independent predictors of response to neoadjuvant immune checkpoint inhibition in early TNBC in GeparNuevo. Ann Oncol. 2020;31:1216-22. https://doi.org/10.1016/j.a nnonc.2020.05.015.

153. Loibl S, Untch M, Burchardi N, Huober J, Sinn BV, Blohmer JU, et al. A randomised phase II study investigating durvalumab in addition to an anthracycline taxane-based neoadjuvant therapy in early triple-negative breast cancer: clinical results and biomarker analysis of GeparNuevo study. Ann Oncol. 2019;30:1279-88. https://doi.org/10.1093/annonc/mdz158.

154. Schmid P, Cortés J, Dent R, Pusztai L, McArthur HL, Kuemmel S, et al. KEYNOTE-522: phase III study of pembrolizumab (pembro) + chemotherapy (chemo) vs placebo (pbo) + chemo as neoadjuvant treatment, followed by pembro vs pbo as adjuvant treatment for early triple-negative breast cancer (TNBC). Ann Oncol. 2019;30:v853-v4. https://doi.org/10.1093/annonc/mdz3 94.003.

155. Finn RS, Qin S, Ikeda M, Galle PR, Ducreux M, Kim TY, et al. Atezolizumab plus Bevacizumab in Unresectable Hepatocellular Carcinoma. N Engl J Med. 2020;382:1894-905. https://doi.org/10.1056/NEJMoa1915745.

156. Socinski MA, Jotte RM, Cappuzzo F, Orlandi F, Stroyakovskiy D, Nogami N, et al. Atezolizumab for first-line treatment of metastatic nonsquamous NSCLC. N Engl J Med. 2018;378:2288-301. https://doi.org/10.1056/NEJMoa1716948.

157. Rini Bl, Plimack ER, Stus V, Gafanov R, Hawkins R, Nosov D, et al. Pembrolizumab plus Axitinib versus Sunitinib for advanced renal-cell carcinoma. N Engl J Med. 2019;380:1116-27. https://doi.org/10.1056/ NEJMoa1816714.

158. Motzer RJ, Robbins PB, Powles T, Albiges L, Haanen JB, Larkin J, et al. Avelumab plus axitinib versus sunitinib in advanced renal cell carcinoma: biomarker analysis of the phase 3 JAVELIN renal 101 trial. Nat Med. 2020;26: 1733-41. https://doi.org/10.1038/s41591-020-1044-8.

159. Makker V, Rasco D, Vogelzang NJ, Brose MS, Cohn AL, Mier J, et al. Lenvatinib plus pembrolizumab in patients with advanced endometrial cancer: an interim analysis of a multicentre, open-label, single-arm, phase 2 trial. Lancet Oncol. 2019;20:711-8. https://doi.org/10.1016/S1470-2045(19)30020-8.

160. Zou Y, Zou X, Zheng S, Tang H, Zhang L, Liu P, et al. Efficacy and predictive factors of immune checkpoint inhibitors in metastatic breast cancer: a systematic review and meta-analysis. Ther Adv Med Oncol. 2020;12: 1758835920940928. https://doi.org/10.1177/1758835920940928.

161. Quintela-Fandino M, Manso Sànchez LM, Holgado Martín E, Moreno MC, Morales Murillo S, Bermejo De Las Heras B, et al. Addition of durvalumab (Dur) upon progression to bevacizumab (Bev) maintenance in advanced HER2-negative (HERNEG) breast cancer (BC): Safety, efficacy and biomarkers. Ann Oncol. 2018:29:ix24. https://doi.org/10.1093/annonc/mdy430.003.

162. Fukuoka S, Hara H, Takahashi N, Kojima T, Kawazoe A, Asayama M, et al. Regorafenib plus Nivolumab in patients with advanced gastric or colorectal Cancer: an open-label, dose-escalation, and dose-expansion phase Ib trial (REGONIVO, EPOC1603). J Clin Oncol. 2020;38:2053-61. https://doi.org/10.12 00/JCO.19.03296. 
163. Shigeta K, Datta M, Hato T, Kitahara S, Chen IX, Matsui A, et al. Dual programmed death Receptor-1 and vascular endothelial growth factor Receptor-2 blockade promotes vascular normalization and enhances antitumor immune responses in hepatocellular carcinoma. Hepatology. 2020;71:1247-61. https://doi.org/10.1002/hep.30889.

164. Ciciola P, Cascetta P, Bianco C, Formisano L, Bianco R. Combining immune checkpoint inhibitors with anti-Angiogenic agents. J Clin Med. 2020;9:675. https://doi.org/10.3390/jcm9030675.

165. Naidoo J, Page DB, Li BT, Connell LC, Schindler K, Lacouture ME, et al. Toxicities of the anti-PD-1 and anti-PD-L1 immune checkpoint antibodies. Ann Oncol. 2015;26:2375-91. https://doi.org/10.1093/annonc/mdv383.

166. Qin L, Li X, Stroiney A, Qu J, Helgager J, Reardon DA, et al. Advanced MRI assessment to predict benefit of anti-programmed cell death 1 protein immunotherapy response in patients with recurrent glioblastoma. Neuroradiology. 2017:59:135-45. https://doi.org/10.1007/s00234-016-1769-8.

167. Kamoun WS, Ley CD, Farrar CT, Duyverman AM, Lahdenranta J, Lacorre DA, et al. Edema control by cediranib, a vascular endothelial growth factor receptor-targeted kinase inhibitor, prolongs survival despite persistent brain tumor growth in mice. J Clin Oncol. 2009;27:2542-52. https://doi.org/10.12 00/JCO.2008.19.9356

168. Chen $\mathrm{X}, \mathrm{Ma} \mathrm{L}$, Wang $\mathrm{X}, \mathrm{Mo} \mathrm{H}, \mathrm{Wu} \mathrm{D}$, Lan B, et al. Reactive capillary hemangiomas: a novel dermatologic toxicity following anti-PD-1 treatment with SHR-1210. Cancer Biol Med. 2019;16:173-81. https://doi.org/10.20892/j. issn.2095-3941.2018.0172.

169. Chelala E, Dirani A, Fadlallah A. Intravitreal anti-VEGF injection for the treatment of progressive juxtapapillary retinal capillary hemangioma: a case report and mini review of the literature. Clin Ophthalmol. 2013;7:2143-6. https://doi.org/10.2147/OPTH.S53243.

170. Chauhan VP, Martin JD, Liu H, Lacorre DA, Jain SR, Kozin SV, et al. Angiotensin inhibition enhances drug delivery and potentiates chemotherapy by decompressing tumour blood vessels. Nat Commun. 2013;4:2516. https://doi.org/10.1038/ncomms3516.

171. Hiratsuka S, Goel S, Kamoun WS, Maru Y, Fukumura D, Duda DG, et al. Endothelial focal adhesion kinase mediates cancer cell homing to discrete regions of the lungs via E-selectin up-regulation. Proc Natl Acad Sci U S A. 2011;108:3725-30. https://doi.org/10.1073/pnas.1100446108.

172. Pinter M, Jain RK. Targeting the renin-angiotensin system to improve cance treatment: implications for immunotherapy. Sci Transl Med. 2017;9: eaan5616. https://doi.org/10.1126/scitransImed.aan5616.

173. Stylianopoulos T, Jain RK. Combining two strategies to improve perfusion and drug delivery in solid tumors. Proc Natl Acad Sci U S A. 2013;110: 18632-7. https://doi.org/10.1073/pnas.1318415110.

174. Goede V, Coutelle O, Neuneier J, Reinacher-Schick A, Schnell R, Koslowsky TC, et al. Identification of serum angiopoietin-2 as a biomarker for clinical outcome of colorectal cancer patients treated with bevacizumab-containing therapy. $\mathrm{Br}$ J Cancer. 2010;103:1407-14. https://doi.org/10.1038/sj.bjc.6605925.

175. Rigamonti N, Kadioglu E, Keklikoglou I, Wyser Rmili C, Leow CC, De Palma M. Role of angiopoietin-2 in adaptive tumor resistance to VEGF signaling blockade. Cell Rep. 2014;8:696-706. https://doi.org/10.1016/j.celrep.2014.06.059.

176. De Palma M, Naldini L. Angiopoietin-2 TIEs up macrophages in tumor angiogenesis. Clin Cancer Res. 2011;17:5226-32. https:/doi.org/10.1158/1 078-0432.CCR-10-0171.

177. D'Souza NM, Fang P, Logan J, Yang J, Jiang W, Li J. Combining radiation therapy with immune checkpoint blockade for central nervous system malignancies. Front Oncol. 2016;6:212. https://doi.org/10.3389/fonc.2016. 00212.

178. Zahra MA, Hollingsworth KG, Sala E, Lomas DJ, Tan LT. Dynamic contrastenhanced MRI as a predictor of tumour response to radiotherapy. Lancet Oncol. 2007:8:63-74. https://doi.org/10.1016/S1470-2045(06)71012-9.

179. Fournier LS, Vanel D, Athanasiou A, Gatzemeier W, Masuykov IV, Padhani AR, et al. Dynamic optical breast imaging: a novel technique to detect and characterize tumor vessels. Eur J Radiol. 2009;69:43-9. https://doi.org/10.101 6/j.ejrad.2008.07.038.

180. Zhang J, Tan X, Zhang X, Kang Y, Li J, Ren W, et al. Efficacy of shear-wave elastography versus dynamic optical breast imaging for predicting the pathological response to neoadjuvant chemotherapy in breast cancer. Eur J Radiol. 2020;129:109098. https://doi.org/10.1016/j.ejrad.2020.109098.

\section{Publisher's Note}

Springer Nature remains neutral with regard to jurisdictional claims in published maps and institutional affiliations.

Ready to submit your research? Choose BMC and benefit from:

- fast, convenient online submission

- thorough peer review by experienced researchers in your field

- rapid publication on acceptance

- support for research data, including large and complex data types

- gold Open Access which fosters wider collaboration and increased citations

- maximum visibility for your research: over $100 \mathrm{M}$ website views per year

At BMC, research is always in progress.

Learn more biomedcentral.com/submissions 